\title{
From lamprey to salamander: an exploratory modeling study on the architecture of the spinal locomotor networks in the salamander
}

\author{
Andrej Bicanski · Dimitri Ryczko • \\ Jean-Marie Cabelguen • Auke Jan Ijspeert
}

Received: 23 March 2012 / Accepted: 20 November 2012 / Published online: 6 March 2013

(C) Springer-Verlag Berlin Heidelberg 2013

\begin{abstract}
The evolutionary transition from water to land required new locomotor modes and corresponding adjustments of the spinal "central pattern generators" for locomotion. Salamanders resemble the first terrestrial tetrapods and represent a key animal for the study of these changes. Based on recent physiological data from salamanders, and previous work on the swimming, limbless lamprey, we present a model of the basic oscillatory network in the salamander spinal cord, the spinal segment. Model neurons are of the HodgkinHuxley type. Spinal hemisegments contain sparsely connected excitatory and inhibitory neuron populations, and are coupled to a contralateral hemisegment. The model yields a large range of experimental findings, especially the NMDAinduced oscillations observed in isolated axial hemisegments and segments of the salamander Pleurodeles waltlii. The model reproduces most of the effects of the blockade of AMPA synapses, glycinergic synapses, calcium-activated potassium current, persistent sodium current, and $h$-current. Driving segments with a population of brainstem neurons yields fast oscillations in the in vivo swimming frequency range. A minimal modification to the conductances involved
\end{abstract}

This article forms part of a special issue of Biological Cybernetics entitled "Lamprey, Salamander Robots and Central Nervous System".

A. Bicanski ( $\square)$. A. J. Ijspeert

Biorobotics Laboratory, School of Engineering, École Polytechnique Fédérale de Lausanne, Station 14, 1015 Lausanne, VD, Switzerland e-mail: andrej.bicanski@epfl.ch

http://biorob.epfl.ch

D. Ryczko

Groupe de Recherche sur le Système Nerveux Central, Département de Physiologie, Université de Montréal, Montréal, QC H3C 3J7, Canada

J.-M. Cabelguen

INSERM U862-Neurocentre Magendie, Motor System Diseases Team, Université de Bordeaux, 146 rue Leo Saignat,

33077 Bordeaux Cedex, France in burst-termination yields the slower stepping frequency range. Slow oscillators can impose their frequency on fast oscillators, as is likely the case during gait transitions from swimming to stepping. Our study shows that a lampreylike network can potentially serve as a building block of axial and limb oscillators for swimming and stepping in salamanders.

Keywords Locomotion - Central pattern generator . Segmental oscillators $\cdot$ Salamander $\cdot$ Lamprey

\section{Introduction}

Central pattern generators (CPGs), i.e., neural networks transforming simple inputs into precisely timed oscillatory signals, are recognized as good models of the neural infrastructure underlying vertebrate locomotion [for review, see Grillner (2003, 2006), Chevallier et al. (2008a); for mammalian studies, see McCrea and Rybak (2008), Daun et al. (2009)]. Some studies suggest that the design of axial locomotor CPGs is evolutionary conservative from limbless vertebrates to tetrapods [for review, see Katz and Harris-Warrick (1999), Falgairolle et al. (2006), Ryczko et al. (2010b)]. This concept recasts the notion that once a well-functioning system has evolved, it is easier to modify it rather than to develop a new system from scratch.

In the endeavor to better understand the evolution of the vertebrate locomotor systems, the salamander plays an intriguing role. This tetrapod resembles the first terrestrial vertebrates and is regarded as an animal from which the evolutionary changes from aquatic to terrestrial locomotion can be inferred [Gao and Shubin (2001); for review, see Grillner and Wallén (1985), Cohen et al. (1988)]. Its repertoire of aquatic and terrestrial locomotor patterns shares similarities 
both with limbless vertebrates and mammals [for review, see Cabelguen et al. (2010)]. The close resemblance between the swimming modes of lampreys (Williams et al. 1989) and salamanders (Frolich and Biewener 1992; Delvolvé et al. 1997) has led to the notion that the neural infrastructure underlying salamander locomotion can - to a first approximation-be viewed as a lamprey nervous system extended by neural centers for the limbs (Ijspeert 2001; Bem et al. 2003; Ijspeert et al. 2005, 2007). Recent experimental data revealed that the global architecture of the salamander axial locomotor CPG is similar to that observed in lampreys but the detailed organization of the network is unknown (Ryczko et al. 2010a).

Even in lower vertebrates the complexity of the nervous system renders it extremely difficult to identify and characterize all neurons at the pre-motoneuron level, that are functionally relevant to locomotion. In the well-studied lamprey this is evidenced by the co-existence of different models of the basic locomotor network. In the models by Grillner and co-workers the lateral inhibitory interneuron is no longer present [compare Wallén et al. (1992) to Kozlov et al. 2007, 2009], while it is still featured in other lamprey models (Mullins et al. 2011). Nevertheless, modeling of the neural infrastructure for locomotion has been singularly successful for the lamprey.

For the salamander, neurophysiological data on spinal interneurons and sensory neurons is scarce. Here we present an exploratory study on the salamander axial CPG architecture based on a lamprey neuron model, extended to account for salamander-specific findings. This minimal axial salamander CPG model outlines one possibility of phylogenetic conservatism of axial locomotor network design. Using a single parameter set across all conditions the model can account for electrophysiological data obtained from isolated axial hemisegments and segments in the salamander Pleurodeles waltlii (Ryczko et al. 2010a). A priori many different configurations of ionic channels could produce neural oscillators (Prinz et al. 2004). However, we take the fact that this model adequately reproduces a variety of pharmacological experiments with a single parameter set as indirect evidence that the underlying rhythm generating composition of ionic channels is adequately represented to a first approximation.

The spinal neurons were built by minimally modifying low to intermediate complexity Hodgkin-Huxley models from studies on the lamprey locomotor system (Grillner et al. 1988; Brodin et al. 1991; Ekeberg et al. 1991; Hellgren et al. 1992; Wallén et al. 1992; Ekeberg 1993; Tråvén et al. 1993; Tegnér et al. 1997; Ullström et al. 1998; Kotaleski et al. 1999a,b; Kozlov et al. 2007, 2009; Huss et al. 2007, 2008). Spinal hemisegments contain 50 sparsely connected excitatory neurons that project to 30 inhibitory neurons. Inhibitory neurons project to all neurons of the contralateral hemisegment. Excitatory neurons target their contralateral counterparts. When activated by a simulated NMDA bath, hemiseg- ments produced in vitro-like frequencies that were faster than in segments. Similarly to biological data blocking reciprocal inhibition between hemisegments led to the emergence of synchronous oscillations, enforced by excitatory crossconnections. Furthermore, blocking the calcium-dependent current $\left(I_{\mathrm{KCaN}}\right)$, hyperpolarization-activated cation current $\left(I_{\mathrm{h}}\right)$, persistent sodium current $\left(I_{\mathrm{NaP}}\right)$ or AMPA synapses had effects on the frequency and duty cycle of oscillations corresponding to those observed experimentally.

Using the same parameter set, we were able to generate in vivo-like frequencies when activating the segmental network with a population of neurons mimicking the influence from the descending reticulospinal (RS) neurons. We show how the frequency range of a segment driven by RS neurons can be shifted to lower frequencies by modifying a single conductance and related calcium inflow and decay rates. With this modification, the segmental circuit could therefore implement a simplified limb oscillator, ${ }^{1}$ which is known to be slower than axial oscillators (Ijspeert et al. 2007). In addition we explore the modulation of these frequencies by varying the strength of the descending NMDA synapses and the strength of the adaptation current, since these might be accessible to the organism through the release of neuromodulators and/or a changing descending pathway configuration. Finally, we show that spinal networks with different intrinsic frequencies can be coupled together and produce phase locked activity. This regime corresponds to the simplified limb oscillator imposing its lower frequency on the fast axial network, as is likely the case during gait transitions from swimming to stepping (Ijspeert et al. 2007).

\section{Methods}

\subsection{The cell model}

We base our neuron model on the lamprey models by Grillner, Ekeberg, and co-workers (Ekeberg et al. 1991; Wallén et al. 1992). The full details of the Hodgkin-Huxley cell model (Hodgkin and Huxley 1952), including passive properties, equations and parameters are given in the Appendix and in Tables 1 and 2. In brief: we adopt a geometry with an initial compartment endowed exclusively with a high density of sodium and potassium channels, reminiscent of the axon hillock, a soma compartment, and one dendritic compartment (cf. Fig. 1A). The initial compartment is necessary to transform spike-like membrane potential oscillations that

\footnotetext{
1 Note that this limb oscillator is a caricature. Here, we are interested only in the frequency range of oscillations. In the salamander, as in tetrapods in general, the limb CPG architecture might actually comprise many individual oscillators, e.g., for flexor and extensor muscle pairs. The architecture of the limb CPG is a separate and complex topic.
} 
Table 1 Neuron parameters and network parameters

\begin{tabular}{|c|c|}
\hline \multicolumn{2}{|l|}{ Neuron parameters } \\
\hline Default cell diameter & $0.00003(\mathrm{~m})$ \\
\hline$g_{\text {core- }}$ S $/ \mathrm{S}$ & $300\left(\mathrm{~S} / \mathrm{m}^{2}\right)$ \\
\hline$g_{\text {core-S/D }}$ & $15\left(\mathrm{~S} / \mathrm{m}^{2}\right)$ \\
\hline$g_{\text {leak }}$ & $16.6\left(\mathrm{~S} / \mathrm{m}^{2}\right)$ \\
\hline$C$ & $0.01\left(\mathrm{~F} / \mathrm{m}^{2}\right)$ \\
\hline$a_{\mathrm{S}}$ & "Default" \\
\hline$a_{\mathrm{IS}}$ & $0.1 *$ as $(\mathrm{m})$ \\
\hline$a_{\mathrm{D}}$ & $10 * a_{S}(\mathrm{~m})$ \\
\hline$U_{\text {rest }}$ & $-0.070(\mathrm{~V})$ \\
\hline \multicolumn{2}{|l|}{ Synaptic parameters } \\
\hline$g_{\text {EIN-EIN-AMPA/NMDA }}$ & $0.0055 / 0.0034(\mu \mathrm{S})$ \\
\hline$g_{\text {EIN-CCIN-AMPA/NMDA }}$ & $0.0030 / 0.0080(\mu \mathrm{S})$ \\
\hline$g_{\text {EINcontra-AMPA/NMDA }}$ & $0.0039 / 0.0003(\mu \mathrm{S})$ \\
\hline$g_{\text {CINNcontra-GLYC }}$ & $0.0045(\mu \mathrm{S})$ \\
\hline$g_{\mathrm{EIN}-\mathrm{EIN}-\mathrm{AMPA} / \mathrm{NMDA}-(\mathrm{STEP})}$ & $0.0040 / 0.0091(\mu S)$ \\
\hline 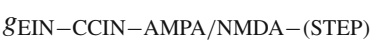 & $0.0030 / 0.0080(\mu \mathrm{S})$ \\
\hline$g_{\text {EINcontra-AMPA/NMDA-(STEP) }}$ & $0.0078 / 0.0022(\mu S)$ \\
\hline$g_{\text {CCINcontra-GLYC-(STEP) }}$ & $0.0038(\mu \mathrm{S})$ \\
\hline$g_{\mathrm{RS}-\mathrm{CPG}-\mathrm{AMPA}-(\mathrm{SWIM})}$ & $0.0064(\mu S)$ \\
\hline$g_{\mathrm{RS}-\mathrm{CPG}-\mathrm{NMDA}-(\mathrm{SWIM})}$ & $0.0021(\mu \mathrm{S}) * w_{\mathrm{RSNMDA}} / 0.26$ \\
\hline$g_{\mathrm{RS}-\mathrm{CPG}-\mathrm{AMPA}-(\mathrm{STEP})}$ & $0.0056(\mu \mathrm{S})$ \\
\hline$g_{\mathrm{RS}-\mathrm{CPG}-\mathrm{NMDA}-(\mathrm{STEP})}$ & $0.0018(\mu \mathrm{S}) * w_{\text {RSNMDA }} / 0.22$ \\
\hline$t_{\mathrm{AMPA} / \mathrm{NMDA} / \mathrm{GLYC}}$ & $0.02 / 0.1 / 0.02(\mathrm{~s})$ \\
\hline$E_{\text {rev-AMPA/NMDA/GLYC }}$ & $0 / 0 /-0.085(\mathrm{~V})$ \\
\hline \multicolumn{2}{|l|}{ Bath parameters } \\
\hline$g_{\mathrm{b}-\mathrm{NMDA}-\mathrm{S}}$ & $0.004 * N_{\text {rec }}(\mu \mathrm{S})$ \\
\hline$N_{\text {rec }}$ & 50 \\
\hline \multicolumn{2}{|l|}{ Connection densities } \\
\hline $\mathrm{EIN}_{\mathrm{ipsi}}$ to $\mathrm{EIN}_{\mathrm{ipsi}}$ & $10(\%)$ \\
\hline $\mathrm{EIN}_{\mathrm{ipsi}}$ to $\mathrm{EIN}_{\text {contra }}$ & $10(\%)$ \\
\hline $\mathrm{EIN}_{\mathrm{ipsi}}$ to $\mathrm{CCIN}_{\mathrm{ipsi}}$ & $10(\%)$ \\
\hline $\mathrm{CCIN}_{\mathrm{ipsi}}$ to $\mathrm{ALL}_{\text {contra }}$ & $14(\%)$ \\
\hline $\mathrm{CCIN}_{\text {ipsi }}$ to $\mathrm{ALL}_{\text {contra-(STEP) }}$ & $15(\%)$ \\
\hline RS to ALL & $55(\%)$ \\
\hline \multicolumn{2}{|l|}{$\begin{array}{l}\text { Standard deviation (mean 1) for } \\
\text { multiplication } \\
\text { parameter variations }\end{array}$} \\
\hline$A_{\mathrm{CaN}-6}$ & 0.04 \\
\hline$B_{\mathrm{CaN}-6}$ & 0.04 \\
\hline$g_{\mathrm{CaN}-6}$ & 0.04 \\
\hline$g_{\mathrm{KCaN}-6}$ & 0.04 \\
\hline$A_{\mathrm{KCaL}-6}$ & 0.04 \\
\hline$B_{\mathrm{KCaL}-6}$ & 0.04 \\
\hline$g_{\mathrm{CaL}}$ & 0.04 \\
\hline$g_{\mathrm{KCaL}}$ & 0.04 \\
\hline NMDA level & 0.04 \\
\hline$A_{\mathrm{NMDA}-6}$ & 0.04 \\
\hline
\end{tabular}

Table 1 continued

\begin{tabular}{ll}
\hline$B_{\mathrm{NMDA}-6}$ & 0.04 \\
$I_{\mathrm{RS}-\text { variance }}$ & 0.5 \\
\hline
\end{tabular}

All parameters are given in standard SI units. $C$ refers to the capacitance, $a$ refers to the area of the neuron, $g$ refers to the conductance, $\tau$ refers to the synaptic decay constant. $N_{\text {rec }}$ is the arbitrarily chosen sensitive to the chemicals within the bath. Note, this number can be set to 1 by compensating with a higher NMDA level. The subscripts $I S, S$, and $D$ refer to the initial neuronal segment, soma, and dendritic compartment, respectively. The subscripts ipsi and contra indicate the ipsilateral and contralateral sides of the segmental network in relation to each other. The subscripts AMPA, NMDA, GLYC (glycinergic), CCIN, EIN refer to the corresponding synaptic and cellular subtypes as described in Fig. 1. $R S$ indicates simulated reticulospinal neurons, $C P G$ or $A L L$ indicates all the neurons in the spinal segment. Hence a subscript of the type $R S$ $A L L$ indicates a value for connections from RS neurons to all segmental neurons. $I_{\mathrm{RS}}$ refers to current injected into reticulospinal neurons. STEP and SWIM indicate any parameters specific to one of the two descending drive setups. Numbers in subscripts refer to the target equations of parameters

do not always reach the full action potential amplitude into full action potentials, with a stereotypical amplitude of 70 $90 \mathrm{mV}$ and a duration of $2-3 \mathrm{~ms}$ from onset to beginning repolarization. Similarly to the studies cited above the soma and dendritic compartment of the model cell are endowed with action potential generating sodium and potassium channels, $\mathrm{N}$ - and L-type calcium channels as calcium sources for two distinct-associated calcium-dependent potassium channels $\left(\mathrm{K}_{\mathrm{Ca}}\right)$. The $\mathrm{K}_{\mathrm{CaL}}$ channel driven by the fast-acting L-type channel constitutes a fast spike-triggered hyperpolarizing current and extends the frequency range of tonic firing, while the slower $\mathrm{N}$-type channel feeds the $\mathrm{K}_{\mathrm{CaN}}$ channel, which plays the role of a delayed spike-triggered hyperpolarising current as the main source of adaptation (cf. Fig. 1B, c) (Gerstner and Kistler 2002; Izhikevich 2007). The presence of N- and L-type calcium channels has been previously demonstrated in amphibians (Bischofberger and Schild 1995; Shen and Slaughter 1999; Perrier and Tresch 2004). In addition, similarly to the studies by Kotaleski et al. (1999a,b), Kozlov et al. (2007, 2009), Huss et al. (2007, 2008) we have included a potassium channel dependent on calcium entering a synaptic or bath-activated NMDA-gated channel. A key hypothesis is that calcium-dependent potassium channels, activated by calcium entering the NMDA synapse, are functionally coupled (and possibly co-located) with the NMDA synapse, as observed in various brain regions in vertebrates (e.g., Faber et al. 2005; Ngo-Anh et al. 2005, see Sect. 4). Note that this coupling between synaptic calcium channels and related $\mathrm{K}_{\mathrm{Ca}}$ channels is a long-standing, experimentally supported feature of lamprey models (Wallén et al. 1992; Huss et al. 2007, 2008), which we inherit due to our overall approach. In the lamprey this coupling remains the best model for NMDA-induced TTX-resistant membrane 
Table 2 Channel parameters and calcium pool parameters

\begin{tabular}{|c|c|}
\hline \multicolumn{2}{|l|}{ Sodium } \\
\hline$\alpha_{\mathrm{ac}-\mathrm{A}-8}$ & $200,000(1 / \mathrm{Vs})$ \\
\hline$\alpha_{\mathrm{ac}-\mathrm{B}-8}$ & $0.045(\mathrm{~V})$ \\
\hline$\alpha_{\mathrm{ac}-\mathrm{C}-8}$ & $0.001(\mathrm{~V})$ \\
\hline$\beta_{\mathrm{ac}-\mathrm{A}-9}$ & $60,000(\mathrm{~V} / \mathrm{s})$ \\
\hline$\beta_{\mathrm{ac}-\mathrm{B}-9}$ & $0.054(\mathrm{~V})$ \\
\hline$\beta_{\mathrm{ac}-\mathrm{C}-9}$ & $0.02(\mathrm{~V})$ \\
\hline$\alpha_{\mathrm{in}-\mathrm{A}-9}$ & $80,000(\mathrm{~V} / \mathrm{s})$ \\
\hline$\alpha_{\text {in }-\mathrm{B}-9}$ & $-0.045(\mathrm{~V})$ \\
\hline$\alpha_{\text {in }-\mathrm{C}-9}$ & $0.001(\mathrm{~V})$ \\
\hline$\beta_{\text {in }-\mathrm{A}-10}$ & $400(1 / \mathrm{s})$ \\
\hline$\beta_{\text {in }-\mathrm{B}-10}$ & $-0.041(\mathrm{~V})$ \\
\hline$\beta_{\text {in }-\mathrm{C}-10}$ & $0.002(\mathrm{~V})$ \\
\hline$E_{\mathrm{rev}-\mathrm{Na}}$ & $0.05(\mathrm{~V})$ \\
\hline$g_{\mathrm{Na}-\mathrm{IS} / \mathrm{S} / \mathrm{D}}$ & $584.5 / 35 / 35\left(\mathrm{~S} / \mathrm{m}^{2}\right)$ \\
\hline \multicolumn{2}{|l|}{ Potassium } \\
\hline$\alpha_{\mathrm{ac}-\mathrm{A}-8}$ & $20,000(1 / \mathrm{Vs})$ \\
\hline$\alpha_{\mathrm{ac}-\mathrm{B}-8}$ & $-0.045(\mathrm{~V})$ \\
\hline$\alpha_{\mathrm{ac}-\mathrm{C}-8}$ & $0.0008(\mathrm{~V})$ \\
\hline$\beta_{\mathrm{ac}-\mathrm{A}-9}$ & $5,000(\mathrm{~V} / \mathrm{s})$ \\
\hline$\beta_{\mathrm{ac}-\mathrm{B}-9}$ & $-0.035(\mathrm{~V})$ \\
\hline$\beta_{\mathrm{ac}-\mathrm{C}-9}$ & $0.0004(\mathrm{~V})$ \\
\hline$E_{\text {rev_K}}$ & $-0.08(\mathrm{~V})$ \\
\hline$g_{\mathrm{K}-\mathrm{IS} / \mathrm{S} / \mathrm{D}}$ & $581 / 116.2 / 116.2\left(\mathrm{~S} / \mathrm{m}^{2}\right)$ \\
\hline \multicolumn{2}{|l|}{$N$-type calcium } \\
\hline$\tau_{\mathrm{ac}}$ & $0.12(\mathrm{~s})$ \\
\hline$p_{\text {ac }- \text { inf }-\mathrm{B}-13}$ & $-0.015(\mathrm{~V})$ \\
\hline$p_{\text {ac }- \text { inf }-\mathrm{C}-13}$ & $-0.0055(\mathrm{~V})$ \\
\hline$\tau_{\text {in }}$ & $0.3(\mathrm{~s})$ \\
\hline$p_{\text {in }- \text { inf }-\mathrm{B}-13}$ & $-0.035(\mathrm{~V})$ \\
\hline$p_{\text {in }- \text { inf }-\mathrm{C}-13}$ & $0.005(\mathrm{~V})$ \\
\hline$E_{\mathrm{rev}-\mathrm{CaN}}$ & $0.05(\mathrm{~V})$ \\
\hline$g_{\mathrm{CaN}-\mathrm{IS} / \mathrm{S} / \mathrm{D}}$ & $0 / 61 / 61\left(\mathrm{~S} / \mathrm{m}^{2}\right)$ \\
\hline \multicolumn{2}{|l|}{ L-type calcium } \\
\hline$\tau_{\mathrm{ac}}$ & $0.001(\mathrm{~s})$ \\
\hline$p_{\text {ac }- \text { inf }-\mathrm{B}-13}$ & $-0.025(\mathrm{~V})$ \\
\hline$p_{\text {ac }- \text { inf }-\mathrm{C}-13}$ & $-0.005(\mathrm{~V})$ \\
\hline$E_{\mathrm{rev}-\mathrm{CaL}}$ & $0.05(\mathrm{~V})$ \\
\hline$g_{\mathrm{CaL}-\mathrm{IS} / \mathrm{S} / \mathrm{D}}$ & $0 / 30 / 30\left(\mathrm{~S} / \mathrm{m}^{2}\right)$ \\
\hline \multicolumn{2}{|l|}{$K_{\mathrm{CaN}}$ Potassium } \\
\hline$B_{\mathrm{z}-5}$ & $5 \times 10$ e-9 (a.u.) \\
\hline$E_{\mathrm{rev}-\mathrm{KCaN}}$ & $-0.085(\mathrm{~V})$ \\
\hline$g_{\mathrm{KCaN}-\mathrm{IS} / \mathrm{S} / \mathrm{D}}$ & $0 / 85 / 85\left(\mathrm{~S} / \mathrm{m}^{2}\right)$ \\
\hline$g_{\mathrm{KCaN}-\mathrm{IS} / \mathrm{S} / \mathrm{D}-\mathrm{STEP}}$ & $0 / 92 / 92\left(\mathrm{~S} / \mathrm{m}^{2}\right)$ \\
\hline
\end{tabular}

Table 2 continued

\begin{tabular}{|c|c|}
\hline$A_{\mathrm{CaN}-\text { bath} / \text { swim/step }}$ & $315 / 315 / 138$ (1/As) \\
\hline$B_{\mathrm{CaN}-\mathrm{bath} / \mathrm{swim} / \text { step }}$ & $0.024 / 0.024 / 0.0218(1 / \mathrm{s})$ \\
\hline \multicolumn{2}{|l|}{$K_{\mathrm{CaL}}$ Potassium } \\
\hline$B_{\mathrm{z}-5}$ & $3 \times 10 \mathrm{e}-7$ (a.u.) \\
\hline$E_{\mathrm{rev}-\mathrm{KCaL}}$ & $-0.085(\mathrm{~V})$ \\
\hline$g_{\mathrm{KCaL}-\mathrm{IS} / \mathrm{S} / \mathrm{D}}$ & $0 / 40 / 40\left(\mathrm{~S} / \mathrm{m}^{2}\right)$ \\
\hline$A_{\mathrm{CaL}-\text { bath} / \text { swim/step }}$ & 1900/1900/1900 (1/As) \\
\hline$B_{\mathrm{CaL}}$ & $0.026(1 / \mathrm{s})$ \\
\hline \multicolumn{2}{|l|}{$\begin{array}{l}\text { Calcium through the NMDA } \\
\text { synapse (Mg-Block) }\end{array}$} \\
\hline$\alpha_{\mathrm{A}-11}$ & $700(1 / \mathrm{s})$ \\
\hline$\alpha_{\mathrm{B}-11}$ & $0.008(\mathrm{~V})$ \\
\hline$\alpha_{\mathrm{C}-11}$ & $0.017(\mathrm{~V})$ \\
\hline$\beta_{\mathrm{A}-12}$ & $10.08(1 / \mathrm{s})$ \\
\hline$\beta_{\mathrm{B}-12}$ & $0.008(\mathrm{~V})$ \\
\hline$\beta_{\mathrm{C}-12}$ & $0.017(\mathrm{~V})$ \\
\hline \multicolumn{2}{|l|}{$K_{\text {CaNMDA }}$ Potassium } \\
\hline$B_{\mathrm{z}-5}$ & $4.8 \times 10 \mathrm{e}-8$ (a.u.) \\
\hline$E_{\mathrm{rev}-\mathrm{KCaNMDA}}$ & $-0.085(\mathrm{~V})$ \\
\hline$g_{\mathrm{KCaNMDA}-\mathrm{IS} / \mathrm{S} / \mathrm{D}-\mathrm{EIN}}$ & $0 / 220 / 0\left(\mathrm{~S} / \mathrm{m}^{2}\right)$ \\
\hline$g_{\mathrm{KCaNMDA}-\mathrm{IS} / \mathrm{S} / \mathrm{D}-\mathrm{CCIN}}$ & $0 / 80 / 0\left(\mathrm{~S} / \mathrm{m}^{2}\right)$ \\
\hline$A_{\text {CaNMDA-EIN/CCIN }}$ & $0.168 / 0.136(1 / \mathrm{As})$ \\
\hline$B_{\text {CaNMDA-EIN/CCIN }}$ & $0.22 / 0.19(1 / \mathrm{s})$ \\
\hline$A_{\mathrm{CaNMDA}-\mathrm{EIN} / \mathrm{CCIN}-\mathrm{STEP}}$ & $1.26 / 1.02$ (1/As) \\
\hline$B_{\text {CaNMDA-EIN/CCIN-STEP }}$ & $1.76 / 1.52(1 / \mathrm{s})$ \\
\hline \multicolumn{2}{|l|}{ Fast persistent sodium } \\
\hline$p_{\mathrm{ac}-\mathrm{inf}-\mathrm{B}-14}$ & $-0.050(\mathrm{~V})$ \\
\hline$p_{\text {ac }- \text { inf }-\mathrm{C}-14}$ & $0.01(\mathrm{~V})$ \\
\hline$p_{\text {in }- \text { inf }-\mathrm{B}-14}$ & $-0.049(\mathrm{~V})$ \\
\hline$p_{\text {in }-\mathrm{inf}-\mathrm{C}-14}$ & $-0.010(\mathrm{~V})$ \\
\hline$\tau_{\mathrm{ac}-\mathrm{inf}}$ & instantaneous \\
\hline$\tau_{\text {in }- \text { inf }-\mathrm{A}-15}$ & $2(\mathrm{~s})$ \\
\hline$\tau_{\text {in }- \text { inf }-B-15}$ & $4.5(\mathrm{~s})$ \\
\hline$\tau_{\text {in }- \text { inf }-C-15}$ & $-0.066(\mathrm{~V})$ \\
\hline$\tau_{\text {in }- \text { inf }-D-15}$ & $0.035\left(\mathrm{~V}^{2}\right)$ \\
\hline$E_{\mathrm{rev}-\mathrm{NaP}}$ & $0.05(\mathrm{~V})$ \\
\hline$g_{\mathrm{NaP}-\mathrm{IS} / \mathrm{S} / \mathrm{D}}$ & $0 / 4.64 / 4.64\left(\mathrm{~S} / \mathrm{m}^{2}\right)$ \\
\hline \multicolumn{2}{|l|}{ h-current } \\
\hline$p_{\text {in }- \text { inf }-\mathrm{B}-14}$ & $-0.075(\mathrm{~V})$ \\
\hline$p_{\text {in }- \text { inf }-\mathrm{C}-14}$ & $-0.0055(\mathrm{~V})$ \\
\hline$\tau_{\text {in }- \text { inf }-\mathrm{A}-15}$ & $0.01(\mathrm{~s})$ \\
\hline$\tau_{\text {in }- \text { inf }-B-15}$ & $0.05(\mathrm{~s})$ \\
\hline$\tau_{\text {in }- \text { inf }-\mathrm{C}-15}$ & $-0.075(\mathrm{~V})$ \\
\hline$\tau_{\text {in }- \text { inf }-\mathrm{D}-15}$ & $0.015\left(\mathrm{~V}^{2}\right)$ \\
\hline
\end{tabular}


Table 2 continued

\begin{tabular}{ll}
\hline$E_{\mathrm{rev}-\mathrm{h}}$ & $-0.055(\mathrm{~V})$ \\
$g_{\mathrm{h}-\mathrm{IS} / \mathrm{S} / \mathrm{D}}$ & $0 / 44.8 / 22.4\left(\mathrm{~S} / \mathrm{m}^{2}\right)$ \\
\hline
\end{tabular}

Parameters for the gating variables of the spike-generating sodium and potassium channels correspond to the ones given in Wallén et al. (1992). Parameters related to the activation and inactivation of the added channels Nap and h are taken from Ref. (Izhikevich 2007). These correspond to the values given in Ref. (Magee 1998; Magistretti and Alonso 1999). For the remaining channels the parameters are taken from Huss et al. (2007). Numbers in parameter subscripts indicate the target equation. Parameter subscripts $a c$ and in specify whether the parameters are for activation and inactivation variables. Parameters named alpha and beta are used to obtain the components of Eq. 3. The subscript inf indicates parameters for the calculation of asymptotic values according to Eq. 4. $g$ refers to conductances, and $E_{\text {rev }}$ refers to reversal potentials

oscillations. Hence, the associated NMDA-calcium pool $\left(\mathrm{Ca}_{\text {NMDA }}\right)$ is modeled as distinct from the $\mathrm{Ca}_{\mathrm{L}}$ and $\mathrm{Ca}_{\mathrm{N}}$ pools. Long period oscillations (cf. Fig. 1E) thus emerge as a consequence of the interplay between NMDA-induced plateau potentials and $\mathrm{K}_{\mathrm{Ca}}$ channels co-located with the NMDA synapse. Note that the period of NMDA-induced oscillations depends on multiple parameters: the ratio of calcium inflow and decay rates, the strength of the $\mathrm{K}_{\mathrm{CaNMDA}}$ conductance, the strength of the NMDA bath, the strength of the NMDA synapse and the density of recurrent connections in the network.

Adding to the above studies we extended the model by the addition of a hyperpolarization activated $h$-current $\left(\mathrm{I}_{\mathrm{h}}\right)$ and a persistent sodium current $\left(I_{\mathrm{NaP}}\right)$ since it has been demonstrated that blocking these channels can, respectively, slow down or abolish oscillatory behavior (Ryczko et al. 2010a). I $\mathrm{h}$ was further demonstrated to be present in salamander motoneurons (Chevallier et al. 2006, 2008b). The default diameter of our tentative salamander locomotor CPG interneurons was chosen as $30 \mu \mathrm{m}$ (Jovanovic and Burke 2004). The NMDA bath activation is implemented in a similar fashion as by Wallén et al. (1992) as trans-membrane conductances modulated by a unitless quantity indicating the level of NMDA in the solution, mimicking a constant steady-state fraction of docked agonist. The NMDA conductance is further multiplied by a variable modeling the voltagedependent block of the NMDA-gated channel by magnesium. Synaptic communication is implemented via spike tracking. Upon detection of a spike in a presynaptic neuron a transmembrane current in the target neuron activates and decays with a given time constant (cf. Table 1). The synaptic delay is set to $1.5 \mathrm{~ms}$, a stereotypical value for monosynaptic connections and in the lower range of values reported for amphibians (Ovsepian and Vesselkin 2006). The frequency range of tonic spiking when a constant current is injected extends from 2 to roughly $90 \mathrm{~Hz}$ (cf. Fig. 1C). The rheobase current is $0.84 \mathrm{nA}$ for the given neuron size. Parameters for the $h$-current have been tuned to allow for the depolarizing overshoot typical for this current (cf. Fig. 1D), as documented for salaman- der motoneurons [Fig. 6 in Chevallier et al. (2006)]. Finally, EPSPs have been modeled to have appropriate amplitudes and decay times (cf. Fig. 1F) (Tråvén et al. 1993).

\subsection{The network}

Figure $1 \mathrm{G}$ depicts the isolated segmental network we modeled. As outlined in the introduction we forego the output elements, i.e., the motoneurons, and consider the activity of excitatory interneuron population as the raw axial locomotor-like CPG output. The network consists of two reciprocally coupled hemisegments-our fundamental building blocks of the locomotor CPG. One hemisegment consists of 50 sparsely interconnected excitatory neurons

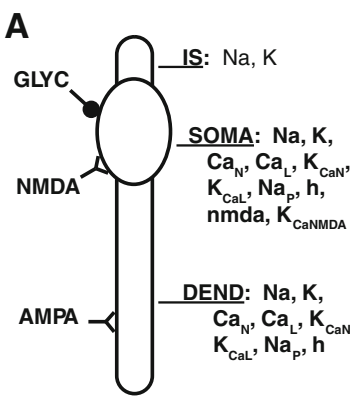

B
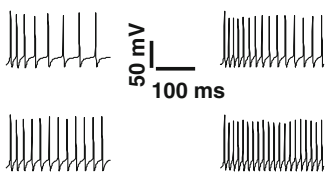

C

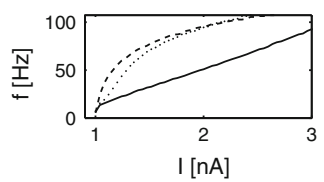

D

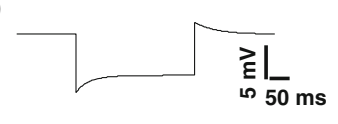

E

$\mathbf{F}$
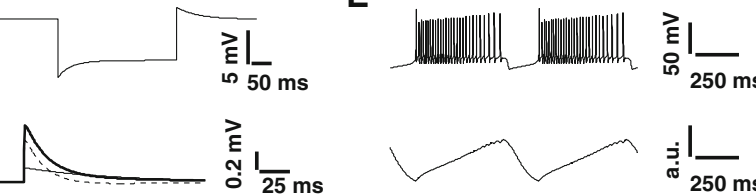

G

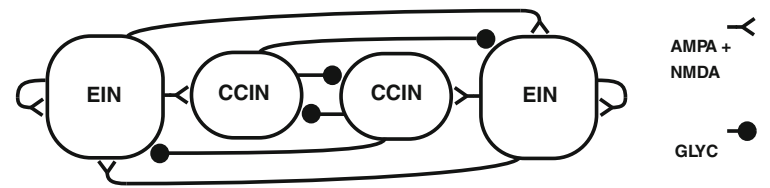

Fig. 1 Neuronal properties of the CPG interneurons and network layout. A A geometric depiction the model neuron, the distribution of synaptic contacts and lists of membrane currents. B Two representative spike trains (left to right, injected current 1.4 and $1.9 \mathrm{nA}$ ) with (upper two panels) and without the adaptation current (lower two pan$e l s)$. C The spiking frequency in response to injected current calculated from the first (dashed line), second (dotted line), and last (solid line) interspike interval. D $I_{\mathrm{h}}$-mediated depolarizing overshoot after hyperpolarization. E A typical NMDA-induced burst in an isolated neuron and the corresponding intracellular calcium concentration for calcium entering the NMDA synapse (in arbitrary units). F EPSPs due to AMPA (dashed curve, elicited in the dendrite), NMDA (solid curve, elicited in the soma) and mixed synapses (solid bold curve). See Appendix for the electrotonic properties of the dendrites. G Organization of the segmental bursting network proposed for the salamander. Two hemisegments, each consisting of 50 excitatory interneurons (EINs) and 30 inhibitory interneurons (CCINs). Excitatory connections consist of AMPA and NMDA synapses. Inhibitory synapses represent glycinergic connections (GLYC) 
[EINs, after Wallén et al. (1992)], which also project to their contralateral counterparts since the findings by Ryczko and co-workers revealed the presence of excitatory crossconnections (Ryczko et al. 2010a). The connection density is $10 \%$ and each synaptic contact consists of one AMPA and one NMDA synapse to the dendritic compartment and the soma, respectively. These EINs project to a pool of 30 inhibitory neurons [CCINs, after Wallén et al. (1992)] within the same hemisegment with $10 \%$ connection density. If two hemisegments are coupled, the CCINs project with $14 \%$ sparseness to all neurons on the contralateral side. The EINs project to their contralateral counterparts with a sparseness of $10 \%$, implementing the excitatory cross-connections. In an extension of this setup, we studied the network activated under conditions more akin to in vivo activity. We added a population 50 additional neurons that project to all segmental neurons with a connection density of $55 \%$, representing a simple implementation of descending reticulospinal (RS) pathways driving the segmental population (Chevallier et al. 2004).

All model parameters are summarized in Tables 1 and 2. Since the connection densities are unknown, they have been chosen freely, i.e., tuned and frozen for all simulations, to obtain the present results. Various connection densities among and within the neuronal subpopulations were tested. The ratio between the number of EINs and CCINs was motivated by the study by Cheng et al. (2002), which gives rough estimates for the number of contralaterally projecting neurons. The topology within the network is not known for the salamander and is inspired by published lamprey models (Wallén et al. 1992; Kozlov et al. 2007). However, cross excitatory projections have been restricted to targeting contralateral EINs in order to facilitate synchronous oscillations in the network when reciprocal inhibition is blocked (Ryczko et al. 2010a). This is a simplifying assumption due to the lack of motoneurons in the model, which could otherwise also be targets for excitatory cross-connections. It has been demonstrated that crossed excitatory connections target contralateral motoneurons or inhibitory interneurons in the lamprey [Buchanan (1982), Buchanan and McPherson (1995), see also Mahmood et al. (2009), for review see Ryczko et al. (2010b)]. The commissural projection to contralateral excitatory neuron remains to be demonstrated even in the lamprey. However in the zebrafish, anatomical data suggests that excitatory commissural interneurons active during slow swimming (the so-called multipolar commissural descending interneurons, "MCoDs") may excite each other through axon collaterals that are in close proximity to contralateral MCoD somata (McLean et al. 2008).

To add noise and to avoid discontinuities the NMDA level in the network rose smoothly with varying delays during the first second of the simulations. This was implemented by multiplying the NMDA level with a sigmoidal function that reached saturation shortly after the onset of the simulation. The slope and offset of this function were set randomly for each neuron in the network, thus excluding a bias toward synchronization from the outset. The values for the conductances, inflow and decay rates related to the different calcium subsystems $\left(\mathrm{Ca}_{\mathrm{L}}, \mathrm{Ca}_{\mathrm{N}}, \mathrm{Ca} \mathrm{NMDA}\right)$ were given a normally distributed spread around appropriate mean values (cf. Table 1).

\subsection{Quantification of locomotor parameters}

Oscillations were smoothed with a running mean spanning $600 \mathrm{~ms}$ for slow NMDA-induced oscillations, and $50 \mathrm{~ms}$ for oscillations evoked by descending drive. Fourier spectra were calculated in order to reveal noteworthy frequency contributions. The duty cycle is calculated as the active interval of this smoothed network output. The network is defined to be active when the smoothed network output reaches $38 \%$ of the maximum amplitude of the oscillation. This threshold is chosen since it yields a duty cycle close to $50 \%$ for segments, in close agreement with visual inspection. The same threshold is then used throughout the data analysis. The cycle duration is identified as the average time between successive onsets of activity. 30 independent instances/individuals of segments (similarly for hemisegments) were used to estimate the mean period of oscillations and their standard deviations, the duty cycles and the stability (see below). Within one type of numerical experiment (e.g., hemisegments under control conditions or hemisegments with a simulated pharmacological channel block), an independent instance constitutes a separate simulation under identical conditions with a newly drawn set of random numbers for all parameters that exhibit a stochastic spread within the neuronal population. These iterations can be thought of a separate individuals. Cycle durations, duty cycles and the stability scores (see below) were averaged across instances.

To measure the stability of the segmental and hemisegmental rhythms we computed autocorrelograms on the average membrane potential trace of the left excitatory neuron population (EINs). A time window of the first $40 \mathrm{~s}$ was crosscorrelated with progressively time-shifted versions of itself. The absolute value of the first peak-to-through difference in the correlogram - the peak-to-through correlation coefficient (henceforth ptcc) — was used as an estimate the rhythmic stability [see Ryczko et al. (2010a), Madriaga et al. (2004)]. Mean values close to 2 and low standard deviations indicate stable oscillations while values closer to zero and high standard deviations indicate less stable oscillations.

\subsection{Implementation}

All simulations and data analyses have been implemented and carried out in Mathworks Matlab 64 bit version 7.13 
under Ubuntu Linux version 10.04 on a Dell Precision T3500 and a local computing cluster with 88 processing cores running Ubuntu Linux version 10.04.

\section{Results}

In the data set of Ryczko et al. (2010a) the cycle duration for NMDA induced oscillations ranged from $4.53 \pm 1.26$ to $11.38 \pm 2.04 \mathrm{~s}$ for segments and $3.43 \pm 0.63$ to $6.78 \pm 1.68 \mathrm{~s}$ for hemisegments bathing in the same NMDA concentration. The variations in cycle duration are most likely due to variations in binding of the perfused NMDA between preparations or possibly due to the dominance of individual oscillators if multiple oscillators with different intrinsic frequencies exist in each hemisegment. Due to the large spread we set the reference value for the cycle duration of NMDA-induced oscillations as the mean experimentally observed period and aimed to reproduce the relative changes as compared to experimental data (Ryczko et al. 2010a). Numerical results are given as mean values \pm standard deviation across 30 independent instances of the same simulation setup.

\subsection{Isolated hemisegments generated rhythmic motor activity}

Throughout the simulations the NMDA stimulation was set to 900 in arbitrary units with normally distributed variations among neurons for each simulation (cf. Table 1). In isolated hemisegments this produced oscillations with a period of $2.81 \pm 1.12 \mathrm{~s}$, with a duty cycle of $69.40 \pm 30.03 \%$ (burst duration $1.95 \pm 0.85 \mathrm{~s}$ ). Figure $2 \mathrm{~A}$ shows a representative plot of the mean activity of the EIN subpopulation and the corresponding raster plot. The oscillation was generated by the temporal overlap of individually bursting neurons (cf. Fig. 2B). Figure 2C shows the autocorrelogram of the representative sample. The averaged measure of rhythmic stability (the ptcc) was estimated at $1.26 \pm 0.47$. Figure $2 \mathrm{D}$ shows the ptcc across all 30 instances of the hemisegment under control conditions. Three large drops in stability are noticeable. These drops correspond to three out of 30 instances that exhibited a very noisy signal. These "outlying regimes" seem to correspond to some cases observed in vitro (Ryczko et al. 2010a). Interestingly, these cases allow for an additional test of the present model (cf. Fig. 7). For isolated hemisegments under control condition these cases led to grossly underestimated cycle durations and duty cycles. Without those the oscillation period would be estimated at $3.32 \pm 0.66 \mathrm{~s}$, with a duty cycle of $69.88 \pm 15.36 \%(2.32 \pm 0.51 \mathrm{~s})$, and the ptcc would increase to $1.39 \pm 0.22$. The experimentally measured mean cycle duration for hemisegments in the study by Ryczko et al. (2010a) was $4.89 \pm 0.95 \mathrm{~s}$. The mean duty cycle was $77.12 \pm 10.10 \%(3.72 \pm 0.74 \mathrm{~s})$.

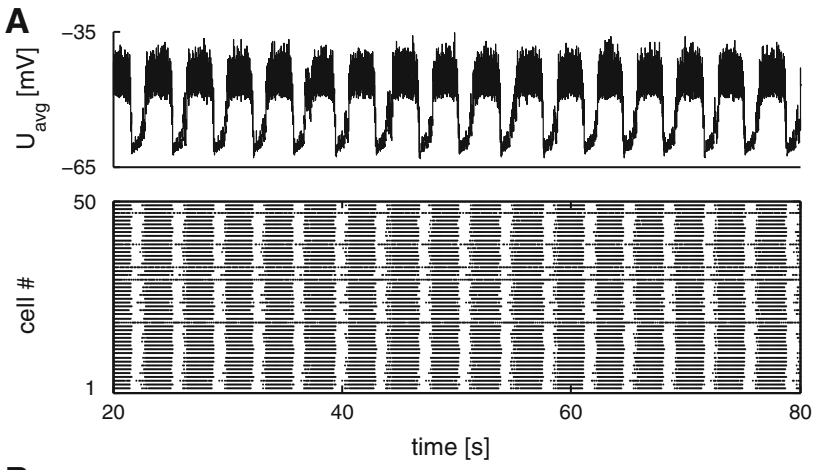

B
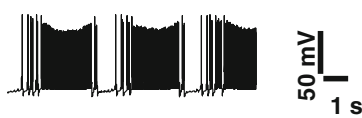

C

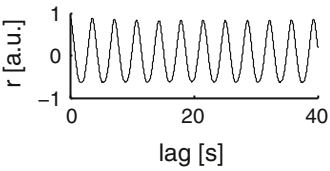

D

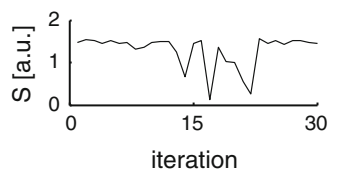

Fig. 2 NMDA-activated isolated hemisegment. A A representative average membrane potential trace of the hemisegmental EIN population (NMDA level 900 in arbitrary units) from one of the 30 instances/individuals calculated for the statistical analysis and a raster plot of the same hemisegmental EIN population. B Model output for single EINs in different bursting regimes. $\mathbf{C}$ The autocorrelogram constructed from the representative average membrane potential trace in (A) in order to estimate rhythmic stability. D The pptc stability measure across 30-independent instances of hemisegments under control conditions

\subsection{Isolated axial segments generated left-right alternating motor patterns}

Connecting two hemisegments with excitatory crossconnections and reciprocal inhibition yielded an oscillating segment that generated alternating bursts of activity. Figure $3 \mathrm{~A}$ shows a representative plot of the mean activity of the left and right EIN subpopulations and the corresponding raster plot. The mean cycle period was $8.84 \pm 0.85 \mathrm{~s}$, with a duty cycle of $49.66 \pm 5.77 \%$ ( $4.39 \pm 0.51 \mathrm{~s})$. Due to the inherent symmetry the duty cycle fluctuated around $50 \%$. Ryczko et al. (2010a) measured $8.08 \pm 1.92 \mathrm{~s}$ for segments with a mean duty cycle of $73.93 \pm 7.29 \%(5.76 \pm 1.60 \mathrm{~s})$. Figure 3B shows representative spike traces from the left and right EIN subpopulations. The autocorrelogram of the representative sample is shown in Fig. 3C. The average ptcc was $1.83 \pm 0.14$ for the segmental oscillations. These were generally more pronounced and stable (yielding a higher score and less variability) than hemisegmental oscillations as is also apparent from a comparison between the representative waveforms (Figs. 2A, 3A) and stability across iterations (Figs. 2D, 3D). 

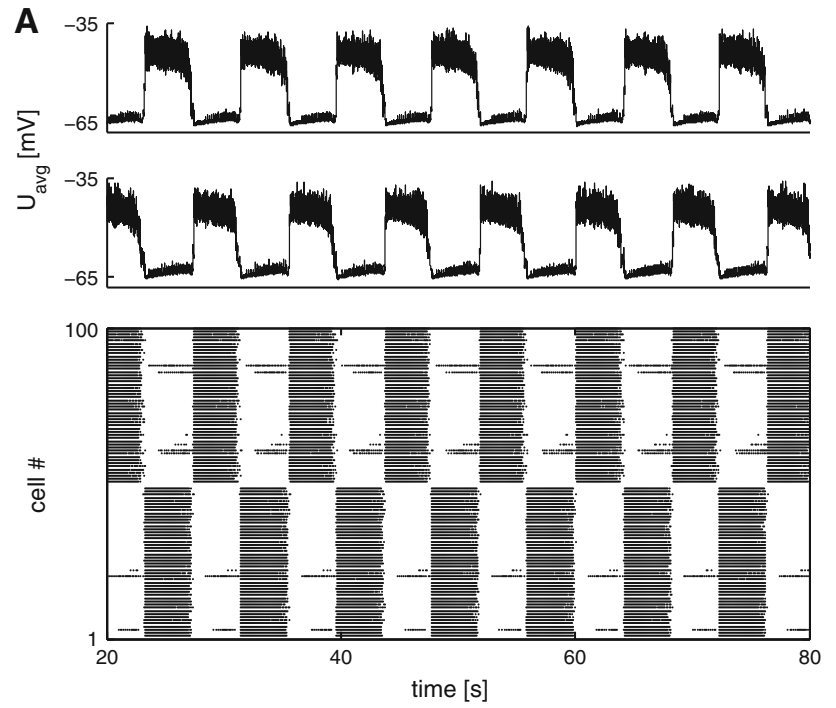

B
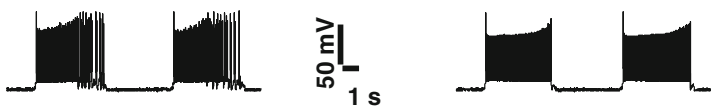

C

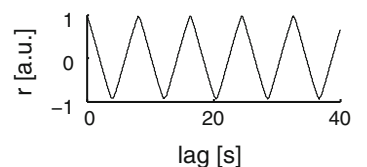

D

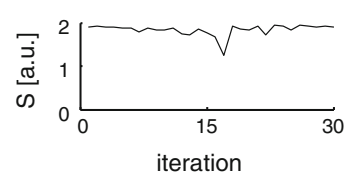

Fig. 3 NMDA-activated isolated segment. A A representative average membrane potential trace of the left and right hemisegmental EIN populations (NMDA level 900 in arbitrary units) from one of the 30 instances/individuals calculated for the statistical analysis and a raster plot of the same populations. B Representative model output for single EINs in different bursting regimes. C The autocorrelogram constructed from the representative average membrane potential trace in (A) in order to estimate rhythmic stability. D The ptcc stability measure across 30 -independent instances of segments under control conditions

For both the model and the experiments isolated hemisegments oscillated faster than complete segments. The hemisegmental period amounted to $31.78 \pm 12.67 \%$ (37.56 $\pm 7.47 \%$ without the outlying regimes) of the average segmental period, compared to the experimental findings of $60.52 \pm$ $11.76 \%$.

\subsection{Suppressing synaptic transmission}

Figure 4 shows representative average membrane potential traces of the left and right segmental EIN subpopulations where the inhibitory cross-connections were turned off $80 \mathrm{~s}$ into the simulations (and reestablished at $120 \mathrm{~s}$ ). Synchronous left and right oscillations emerged rapidly, which strongly resemble the waveforms observed for hemisegments. Turning the reciprocal inhibition back on reestablished the standard segmental regime. Segmental oscillations were unaffected by the excitatory crossconnections due to the overwhelming influence of the inhibitory synapses. Blocking glycinergic synapses in the present model had no effect on isolated hemisegments since there was no connection from CCINs to EINs in the same hemisegment. Without inhibition a segment acted like two synchronized hemisegments.

Figure 5A-E shows from left to right representative waveforms, raster plots and Fourier spectra for the hemisegmental network with decreasing strength of the AMPA synapses. The hemisegmental rhythm disappeared completely in $53.33 \%$ of the 30 iterations under full AMPA blockade (synaptic weight set to zero, Fig. 5E) and was markedly distorted in the remaining iterations (ptcc $0.75 \pm 0.65$ ). Similarly to the experimental data the stability of the rhythm decreased with decreasing AMPA synapse strength. The segmental rhythm (not shown) continued to exhibit anti-phase oscillations imposed by the strong reciprocal inhibition. In the absence of reciprocal inhibition NMDA-evoked EPSPs alone were not sufficient to elicit bursting activity in the network. At least in hemisegments the fast AMPA synapses were necessary as an additional depolarizing component and as a means to facilitate synchronization.

\subsection{The effect of channel blocks}

Figure 6A shows a representative plot of the mean activity of the hemisegmental EIN subpopulation and the corresponding raster plot where $I_{\mathrm{KCaN}}$ has been blocked. Blocking this current has an effect similar to the experimentally observed effect of apamine (Ryczko et al. 2010a). Importantly the average ptcc increased and showed less variability $(1.37 \pm 0.04$, cf. Fig. $6 \mathrm{C})$, showing that the rhythmic stability increased with respect to isolated hemisegments under control conditions. The cycle duration and duty cycle for hemisegments were $5.01 \pm 0.86 \mathrm{~s}$, and $74.85 \pm 13.77 \%$ (3.75 $\pm 0.96 \mathrm{~s})$, respectively. Comparing to hemisegments under control conditions with removed outlying regimes, the variability of the ptcc still decreased. Furthermore, the simulated application of apamine to these outlying regimes allowed for the test of the model under an additional condition. Ryczko et al. (2010a) reported that hemisegments activated by NMDA could sometimes fail to exhibit oscillations, but that application of apamine led to the emergence of oscillations in these cases. Figure 7 shows that the model reproduces this effect. The simulated addition of the apamine to the NMDA-bath halfway through the simulations transformed noisy, non-rhythmic hemisegment activity into clean oscillations.

In the segmental case, the simulated application of apamine (Fig. 8) lead to an increase in cycle duration $(10.66 \pm 1.20 \mathrm{~s})$. The duty cycle remained largely unchanged at $50.00 \pm 6.47 \%(5.33 \pm 0.69 \mathrm{~s})$. The stability measure 


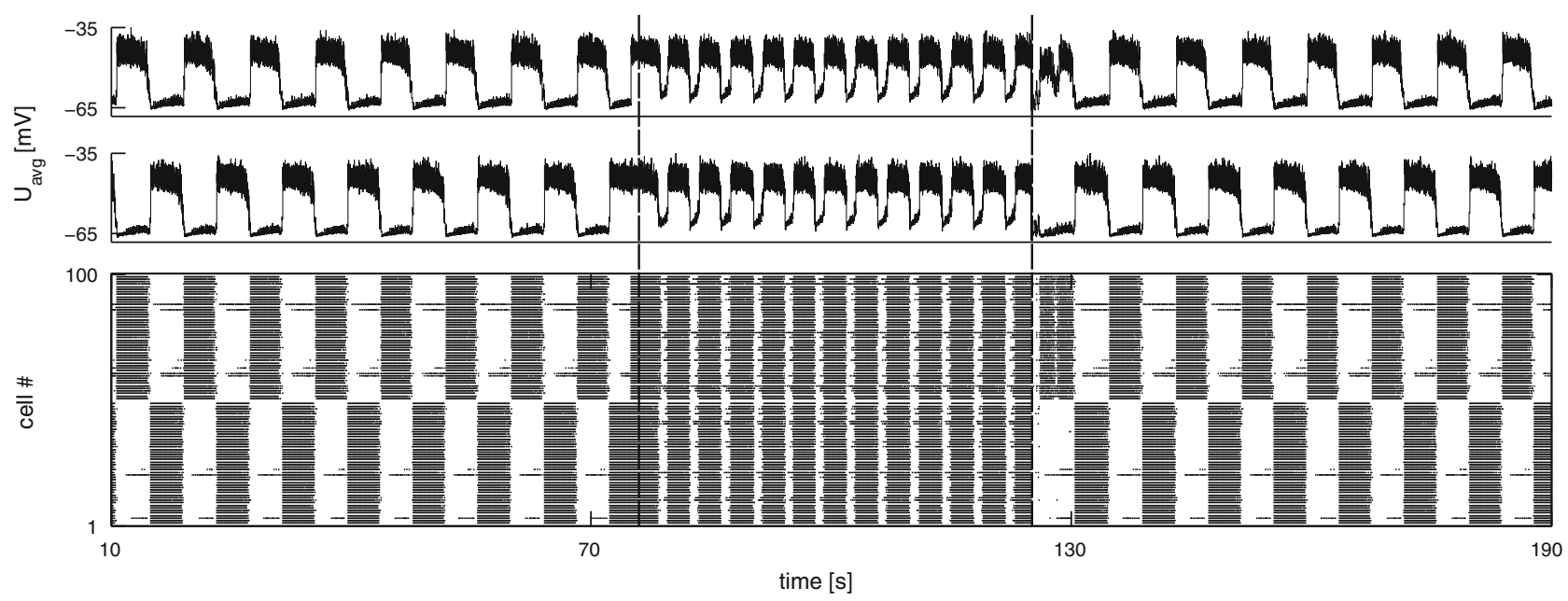

Fig. 4 The effect of glycinergic inhibitory cross-connections. A representative average membrane potential trace of segmental left and right EIN populations where the inhibitory cross-connections are turned off at the $80 \mathrm{~s}$ mark and reinitialized at the $120 \mathrm{~s}$ mark (dashed lines). The lower panel shows the corresponding raster plot
A

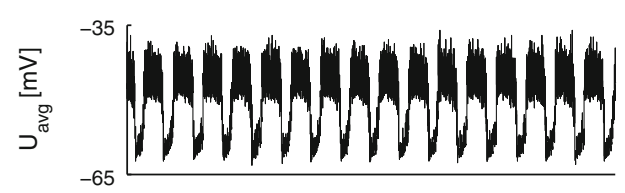

B

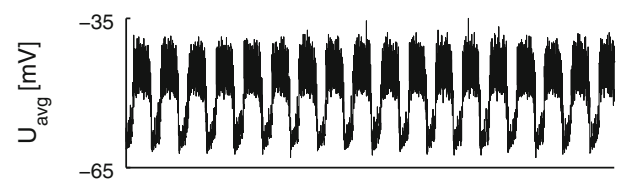

C

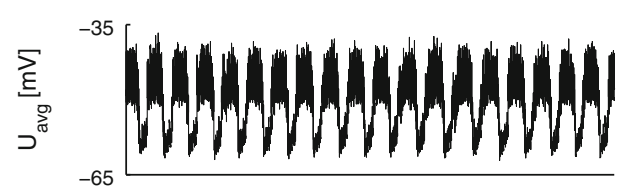

D

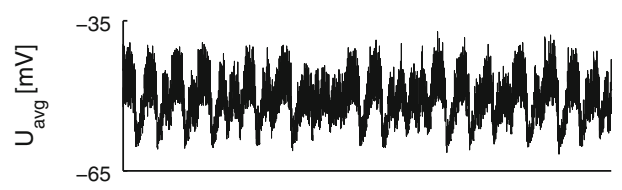

E

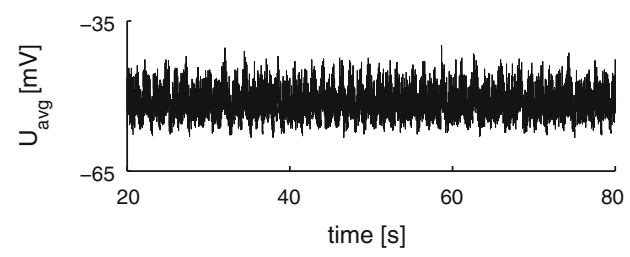

Fig. 5 The effect of suppressing the excitatory AMPA synapse in hemisegments. A-E A representative average membrane potential trace of the spiking activity of hemisegmental EIN population, the corresponding raster plot and the Fourier spectrum of the average membrane
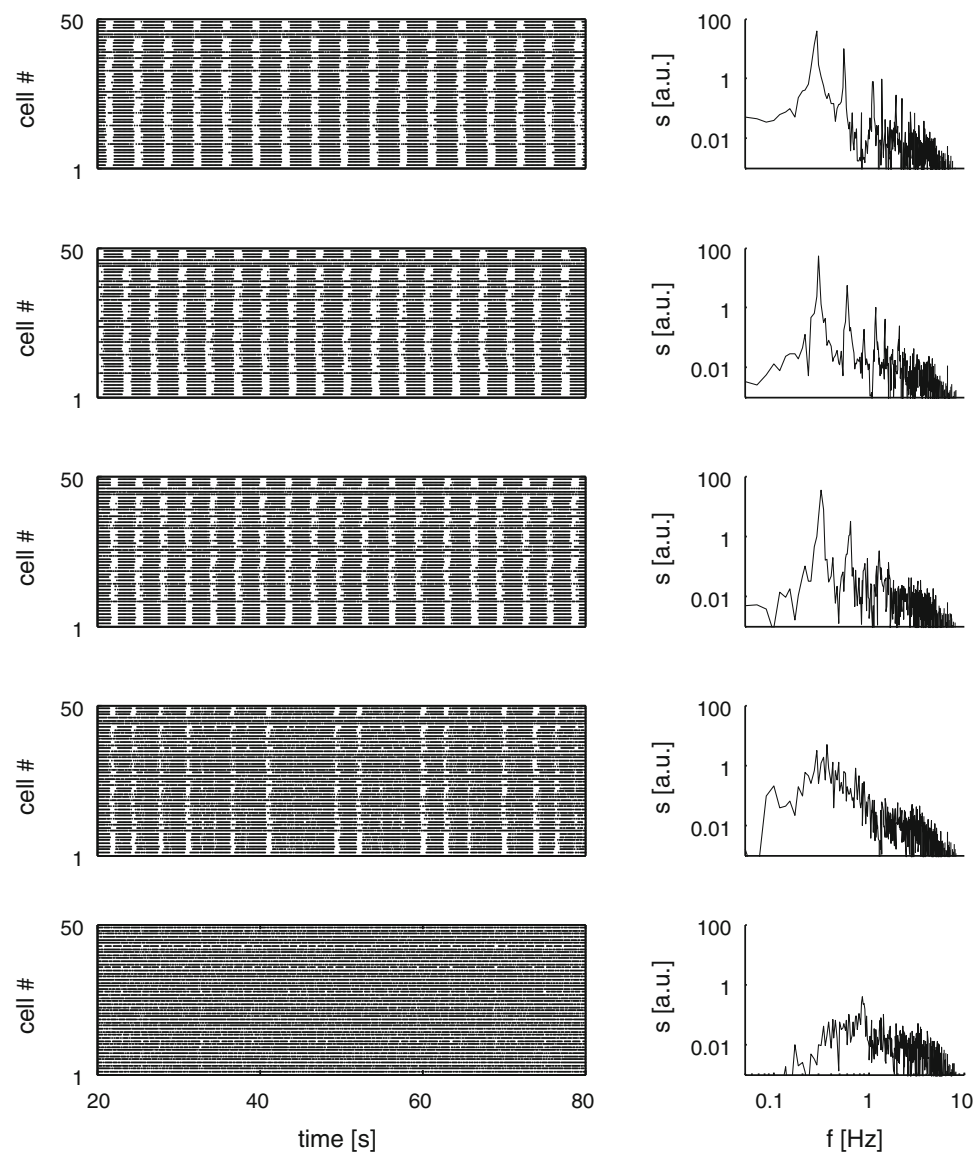

potential for $100 \%$ (ptcc 1.51), $75 \%$ (ptcc 1.56), $50 \%$ (ptcc 1.51), $25 \%$ (ptcc 0.62 ), and $0 \%$ (ptcc 0.37 ) strength of the default synaptic AMPA weight 

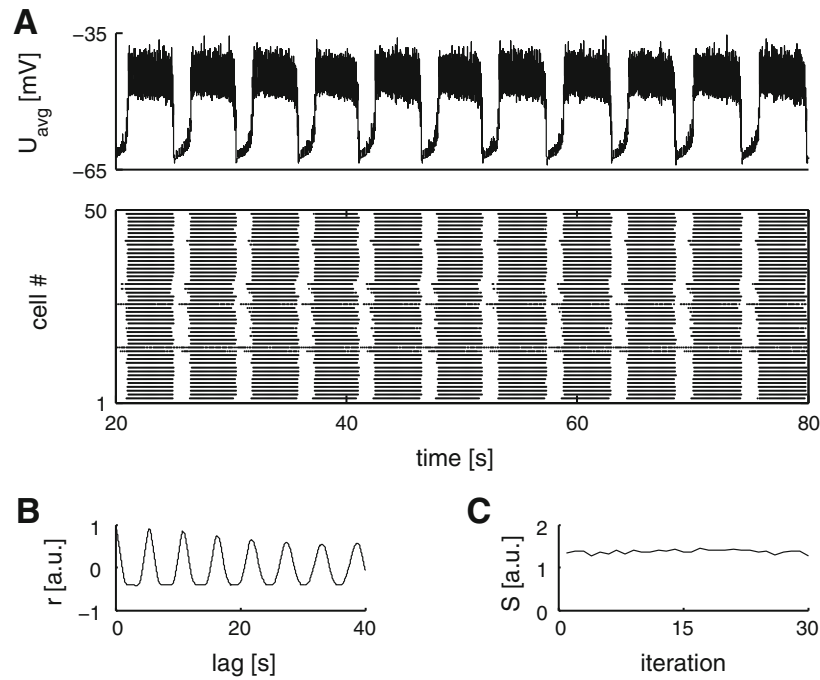

Fig. 6 NMDA-activated isolated hemisegment with $I_{\mathrm{KCaN}}$ blocked. A A representative average membrane potential trace of the hemisegmental EIN population (NMDA level 900 in arbitrary units) from one of the 30 instances/individuals calculated for the statistical analysis and a raster plot of the same hemisegmental EIN population. B The autocorrelogram constructed from the representative average membrane potential trace in (A) in order to estimate rhythmic stability. C The pptc stability measure across 30-independent instances of hemisegments with $I_{\mathrm{KCaN}}$ blocked

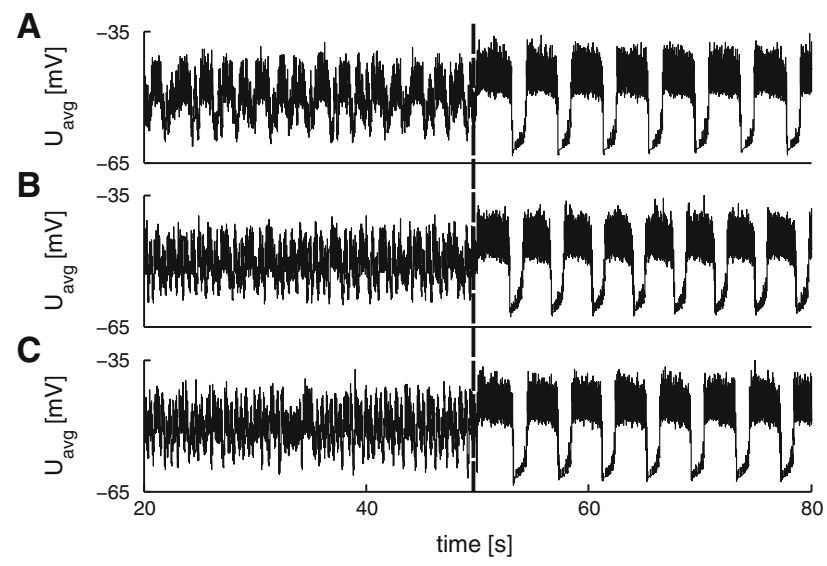

Fig. 7 Noisy isolated hemisegments with delayed simulated addition of apamine to the NMDA-bath. A-C Oscillations emerge in noisy instances (individuals 14, 17, 22) of isolated hemisegments under control conditions after the delayed simulated addition of apamine (dashed line) to the NMDA-bath (NMDA level 900 in arbitrary units)

yielded a ptcc value of $1.85 \pm 0.08$. The increase in rhythmic stability in the segmental case was not pronounced since segmental oscillations were already very stable under control conditions (see Sect. 4). Ryczko et al. (2010a) measured $9.42 \pm 2.28 \mathrm{~s}$ for segments with a mean duty cycle of $64.3 \pm 7.09 \%(5.95 \pm 0.94 \mathrm{~s})$.

Blocking $I_{\mathrm{h}}$ in addition to $I_{\mathrm{KCaN}}$ (corresponding to the application of apamine and ZD 7288) yielded results in line with the expected effect of the $I_{\mathrm{h}}$ (not shown). Except

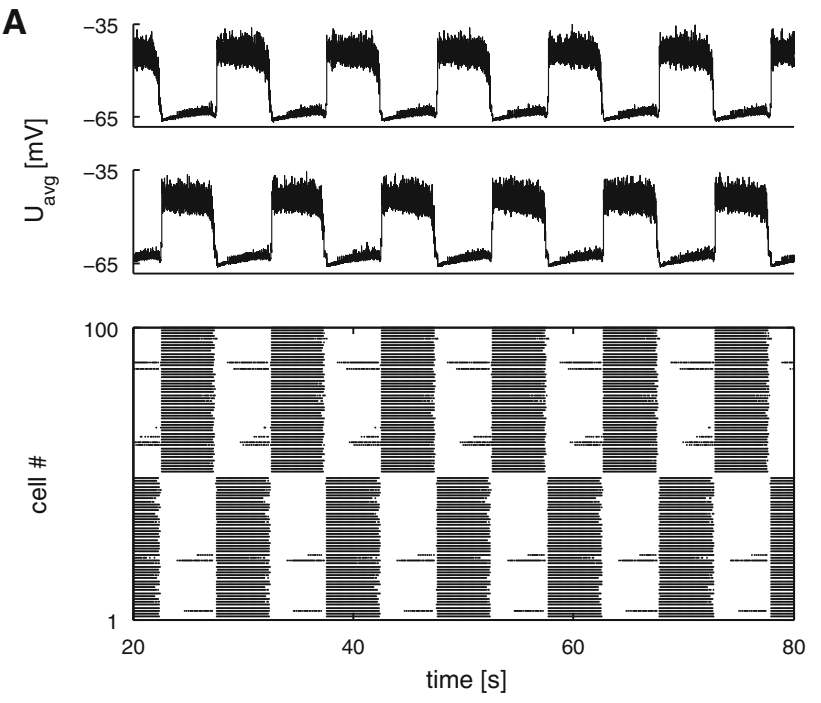

B

C
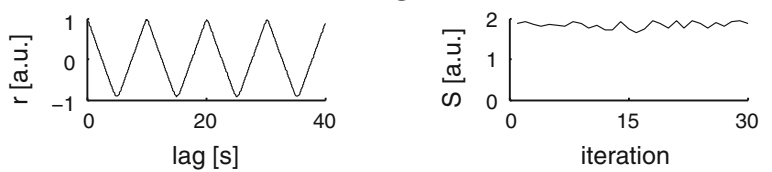

Fig. 8 NMDA-activated isolated segment with $I_{\mathrm{KCaN}}$ blocked. A A representative average membrane potential trace of the left and right hemisegmental EIN populations (NMDA level 900 in arbitrary units) from one of the 30 instances/individuals calculated for the statistical analysis and a raster plot of the same populations. B The autocorrelogram constructed from the representative average membrane potential trace in (A) for the estimation of rhythmic stability. $\mathbf{C}$ The pptc stability measure across 30 -independent iterations of segments with $I_{\mathrm{KCaN}}$ blocked

for a longer cycle duration the results closely resembled the corresponding apamine results (cf. Figs. 6, 8). Compared to the apamine case the hemisegmental cycle duration increased to $5.65 \pm 0.81 \mathrm{~s}$. The duty cycle decreased slightly to $69.20 \pm 10.62 \%(3.91 \pm 0.6 \mathrm{~s})$ and the stability score increased to $1.55 \pm 0.67$. Segments with blocked $h$ and $\mathrm{K}_{\mathrm{CaN}}$ currents remained largely unchanged, with an average cycle duration of $10.83 \pm 1.06 \mathrm{~s}$, a duty cycle of $48.48 \pm 5.00 \%$ $(5.25 \pm 0.54 \mathrm{~s})$ and a stability score of $1.80 \pm 0.10$.

Finally, in accordance with the observation that Nap can control the excitability at sub-threshold potential (Llinás 1980; Stafstrom et al. 1982; Llinás 1988) —and the results reported by Ryczko et al. (2010a) — the simulated blockade of the Nap current with riluzole abolished bursting in both segments and hemisegments in our simulations. The NMDAinduced depolarization was insufficient to induce oscillations if the background elevation of the membrane potential and the increased excitability due Nap were removed (not shown). As such, $I_{\mathrm{NaP}}$ can control cellular rhythmic properties by triggering burst initiation. 


\subsection{In vivo-like rhythms}

The above results reflect in vitro activity of the basic salamander spinal networks. In vivo the salamander (Pleurodeles waltlii) exhibits two primary locomotor modes [for review, see Chevallier et al. (2008a)]. Stepping frequencies have been observed between 0.39 and $1.66 \mathrm{~Hz}$, while swimming frequencies range from 1.33 to $4.37 \mathrm{~Hz}$ (Chevallier et al. 2004). For individual animals these frequency ranges usually do not overlap and also depend on body size. Both these frequency ranges lie notably above frequencies typically observed in vitro in fictive locomotion experiments (Ryczko et al. 2010a).

To investigate how in vivo-like rhythms might be generated, while preserving the in vitro results reported above, we added a separate neuronal population of 50 RS neurons with excitatory glutamatergic projections to all CPG interneurons (density $55 \%$ ) (Buchanan and Grillner 1987; Brodin et al. 1988; Ohta and Grillner 1989; Brocard and Dubuc 2003; Chevallier et al. 2004). The default segmental network used throughout the reproduction of experimental findings was not modified for this. No parameters were changed. RS neurons were driven with a constant input current with normally distributed variations in strength. Numerous parameter combinations were tested in order to determine the broadest range of fast frequencies obtainable with a simple scaling law. These parameters included the descending connection densi-
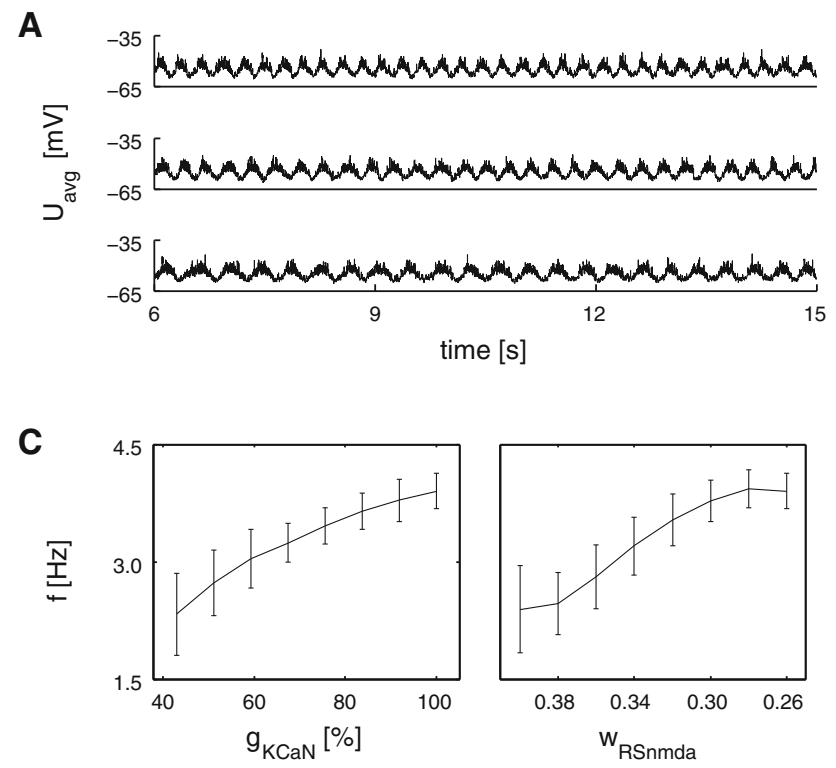

Fig. 9 Segments activated by descending drive generated high frequency oscillations in the in vivo swimming range. A Three representative average membrane potential traces of the left segmental EIN populations (reticulospinal population activated by $1.7 \mathrm{nA}$-injected current). Segmental frequencies and $I_{\mathrm{KCaN}}$ modulation in spinal neurons top to bottom are $3.69 \mathrm{~Hz}$ at $100 \% I_{\mathrm{KCaN}}, 3.19 \mathrm{~Hz}$ at $75 \% I_{\mathrm{KCaN}}$, and $2.5 \mathrm{~Hz}$ at $50 \% I_{\mathrm{KCaN}}$. B Raster plots of spinal (inhibitory neurons not shown) and reticulospinal populations, top to bottom corresponding ties, variations in synaptic strength and target compartment for descending AMPA and NMDA synapses, drive current strength and variance to the RS population, and varying the strength of the $\mathrm{K}_{\mathrm{CaN}}$ current in the spinal neurons (mimicking the release of neuromodulators).

Figures 9 and 10 summarize the results. The broadest and most stable in vivo range of high frequencies $(2.33 \pm 0.52 \mathrm{~Hz}$ to $3.90 \pm 0.23 \mathrm{~Hz}$ ) was obtained by scaling the strength of $\mathrm{K}_{\mathrm{CaN}}$ current. Scaling down this current reduced its capability to contribute to burst termination and thus prolonged the oscillation. However, a similar frequency range could be achieved by scaling the strength of the descending NMDA synapse $(2.39 \pm 0.55 \mathrm{~Hz}$ to $3.90 \pm 0.23 \mathrm{~Hz})$. Weaker NMDA synapses produce weaker NMDA EPSP plateaus (Wallén et al. 1992; Tråvén et al. 1993) and thus less calcium needed to accumulate to terminate the burst. Note that the NMDAcalcium-dependent burst termination only constitutes one contributing factor to burst termination under these in vivolike conditions. Although it dominates when the neurons are activated by the NMDA bath, the adaptation current $I_{\mathrm{KCaN}}$ becomes more important when neurons are activated by descending drive. Segmental oscillations then rely on escape from contralateral inhibition and oscillations cease when the inhibition is blocked.

Figure 9A shows three representative average membrane potential traces of the left EIN subpopulation, corresponding

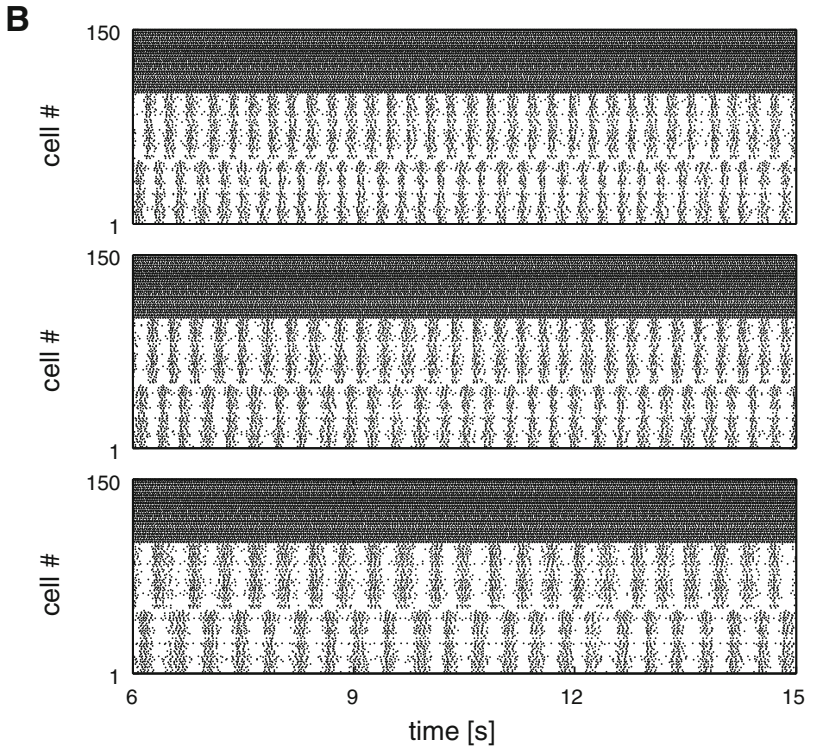

to the membrane potential traces in A. Cells 1-100 depict the spinal population, cells 101-150 depict the driving reticulospinal population. C (left) Frequency of the segmental network oscillations as a function of the $I_{\mathrm{KCaN}}$ modulation; (right) Frequency of the segmental network oscillations as a function of the strength of the descending NMDA synapse. $w_{\text {RSnmda }}$ indicates the multiplicative factor to the default NMDA weight. Error bars indicate the standard deviation across 30 instances/individuals 

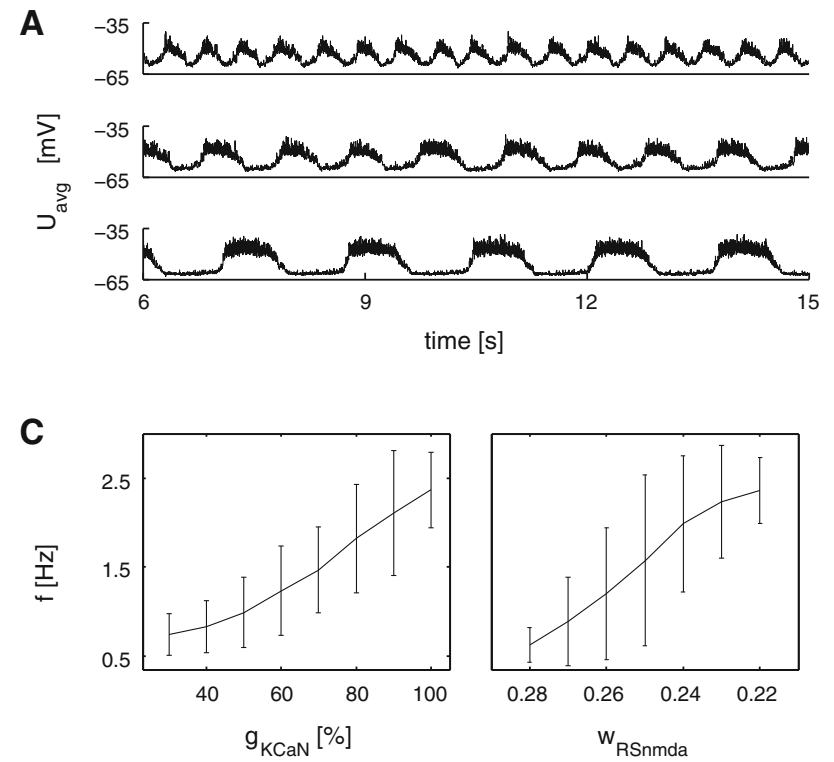

Fig. 10 Segments activated by descending drive generated low frequency oscillations in the in vivo stepping range. A Three representative average membrane potential traces of the left segmental EIN populations (reticulospinal population activated by $1.6 \mathrm{nA}$-injected current). Segmental frequencies and $I_{\mathrm{KCaN}}$ modulation in spinal neurons top to bottom are $2.19 \mathrm{~Hz}$ at $100 \% I_{\mathrm{KCaN}}, 1.04 \mathrm{~Hz}$ at $70 \% I_{\mathrm{KCaN}}$, and $0.60 \mathrm{~Hz}$ at $40 \% I_{\mathrm{KCaN}}$. B Raster plots of spinal (inhibitory neurons not shown) and reticulospinal populations, top to bottom corresponding to the mem-

to three examples from the range of high frequencies $(3.69 \mathrm{~Hz}$ at $100 \% I_{\mathrm{KCaN}}, 3.16 \mathrm{~Hz}$ at $75 \% I_{\mathrm{KCaN}}$, and $2.50 \mathrm{~Hz}$ at $\left.50 \% I_{\mathrm{KCaN}}\right)$. Figure $9 \mathrm{~b}$ shows the corresponding raster plots, including the RS population. Figure 9c shows the relationship between the frequency of segmental oscillations and the strength of the $\mathrm{K}_{\mathrm{CaN}}$ current or the strength of the descending NMDA synapse, respectively. The $\mathrm{K}_{\mathrm{CaL}}$ current remained unchanged in all cases. Most neurons fired bursts of variable length and both $\mathrm{K}_{\mathrm{CaN}}$ and $\mathrm{K}_{\mathrm{CaNMDA}}$ channels contributed to burst termination. This was in line with the fact that both the descending NMDA synapse and the strength of the $\mathrm{K}_{\mathrm{CaN}}$ current could be used to scale the oscillation frequency.

To generate oscillations in the lower in vivo stepping frequency range a minor modification to the segmental neurons was added. The $\mathrm{Ca}_{\mathrm{N}}$ calcium inflow was reduced, thus reducing its contribution to burst termination and the $\mathrm{Ca}_{\mathrm{NMDA}}$ calcium inflow and decay rates were slightly increased (cf. Table 1). These minimal modifications allowed for the emergence of the lower frequency range akin to the range observed in vivo for stepping $(0.74 \pm 0.24 \mathrm{~Hz}$ to $2.37 \pm 0.43 \mathrm{~Hz}$, with $\mathrm{I}_{\mathrm{KCaN}}$ scaling, $0.63 \pm 0.19 \mathrm{~Hz}$ to $2.37 \pm 0.43 \mathrm{~Hz}$, with scaling of the descending NMDA synapse). Figure 10A shows three representative average membrane potential traces of the left EIN subpopulation, corresponding to three example frequencies from the range of lower frequencies $(2.19 \mathrm{~Hz}$ at $100 \% \mathrm{I}_{\mathrm{KCaN}}, 1.04 \mathrm{~Hz}$ at $70 \% \mathrm{I}_{\mathrm{KCaN}}$, and $0.60 \mathrm{~Hz}$ at $40 \%$

\section{B}

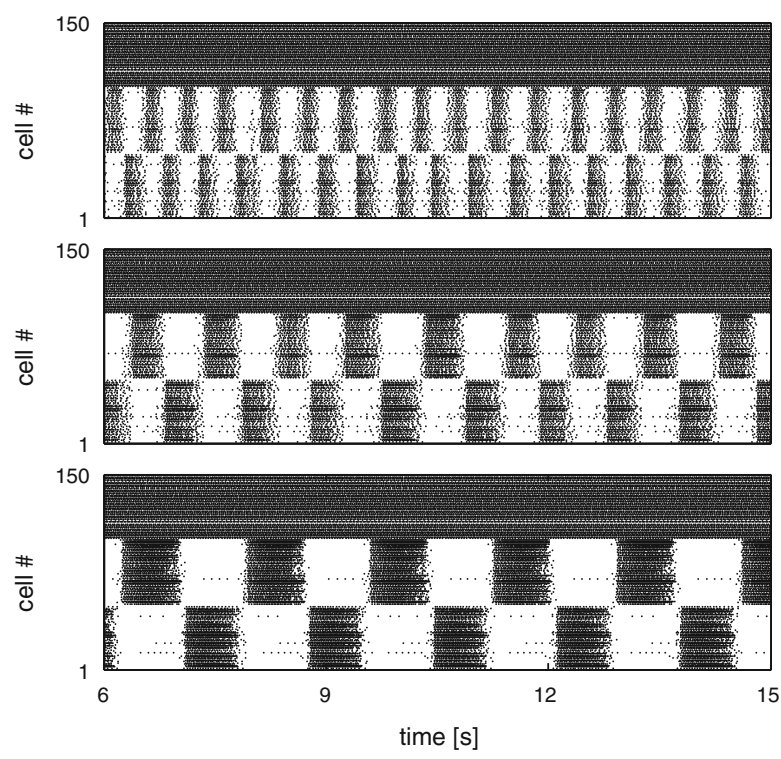

brane potential traces in (A). Cells 1-100 depict the spinal population, cells 101 through 150 depict the reticulospinal population. C (left) Frequency of the segmental network oscillations as a function of the $I_{\mathrm{KCaN}}$ modulation; (right) Frequency of the segmental network oscillations as a function of the strength of the descending NMDA synapse. $w_{\text {RSnmda }}$ indicates the multiplicative factor to the default NMDA weight. Error bars indicate the standard deviation across 30 instances/individuals

$\left.\mathrm{I}_{\mathrm{KCaN}}\right)$. Figure 10B shows the corresponding raster plots, including the RS population. Figure 10C shows the relationship between the frequency of segmental oscillations and the strength of the $\mathrm{K}_{\mathrm{CaN}}$ current or the strength of the descending NMDA synapse respectively.

While a priori a possibility, the scaling of the NMDA synapse would imply that more NMDA EPSPs lead to slower oscillations. Thus to reconcile the present NMDA-dynamics (after Wallén et al. (1992)) with the experimental datum that the spiking frequency of RS neurons correlates positively with the locomotor frequency in lampreys (Brocard et al. 2010) and likely also in salamanders (Cabelguen et al. 2003) we conducted further simulations where the NMDAcalcium inflow rate scaled heuristically with RS frequency. This resulted in a non-linear increase of calcium inflow at the NMDA synapse with increasing NMDA stimulation (see Huss et al. (2008) for a related mechanism). Other hypotheses are outlined in Sect. 4. Figure 11A shows three representative raster plots for stepping-like frequencies. The RS population was activated by $1.7,2.0$, and $2.3 \mathrm{nA}$ injected current, respectively. In response to these injected currents, RS neurons discharged at a mean frequency of $49.0,62.5$, and $75.8 \mathrm{~Hz}$. The corresponding segmental frequencies were $0.63,0.90$, and $1.20 \mathrm{~Hz}$. Figure 11B shows the resulting positive correlation between the current injected into the RS neurons, the mean RS spiking frequency, and the segmental frequency for 

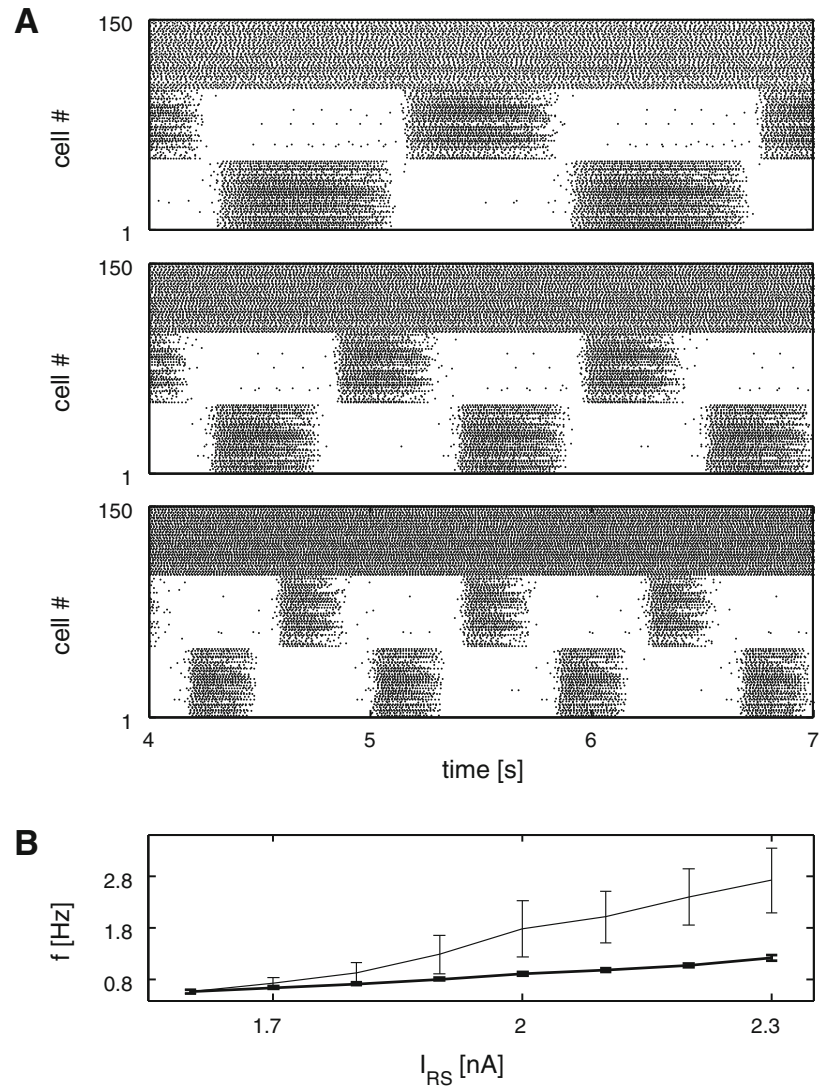

Fig. 11 Increasing the reticulospinal (RS) drive increased the oscillation frequency in segments with scaled NMDA-calcium inflow A three representative raster plots of the segmental EIN populations (reticulospinal population activated by $1.7,2.0$, and $2.3 \mathrm{nA}$ injected current, respectively, corresponding to mean RS spiking frequencies of $49.0,62.5$, and $75.8 \mathrm{~Hz}$ ). Segmental frequencies top to bottom are $0.63,0.90$, and $1.20 \mathrm{~Hz}$ (in vivo stepping range, CaNMDA decay scales linearly). Cells 1-100 depict the spinal population, cells 101 through 150 depict the reticulospinal (RS) population. B Frequency of the segmental network oscillations as a function of the current injected into reticulospinal neurons. Non-linear CaNMDA-inflow scaling of spinal neurons without (bold line), and with added linear $\mathrm{Ca}_{\mathrm{NMDA}}$-decay scaling (regular). Error bars indicate the standard deviation across 30 instances/individuals

a non-linearly scaling calcium inflow (cf. Appendix) with and without additional linear scaling of the NMDA-calcium decay. All parameters were the same as for Fig. 10 (including RS neurons). The AHP strength stayed constant at $50 \%$ of its default value, $\mathrm{w}_{\mathrm{RS} n m d a}$ was set to 0.24 .

Finally, as a proof of concept we coupled two segments, one was initialized with parameters corresponding to low frequencies (simplified limb oscillator-cf. footnote 1) and one with the default/fast frequency configuration (axial oscillator). This setup was based on the fact that during stepping the frequency of the whole locomotor network (the limb networks and the axial network) is low. In other words, the slow stepping frequencies are imposed on the axial network. A simple excitatory connection (density $14 \%$ ) from the limb
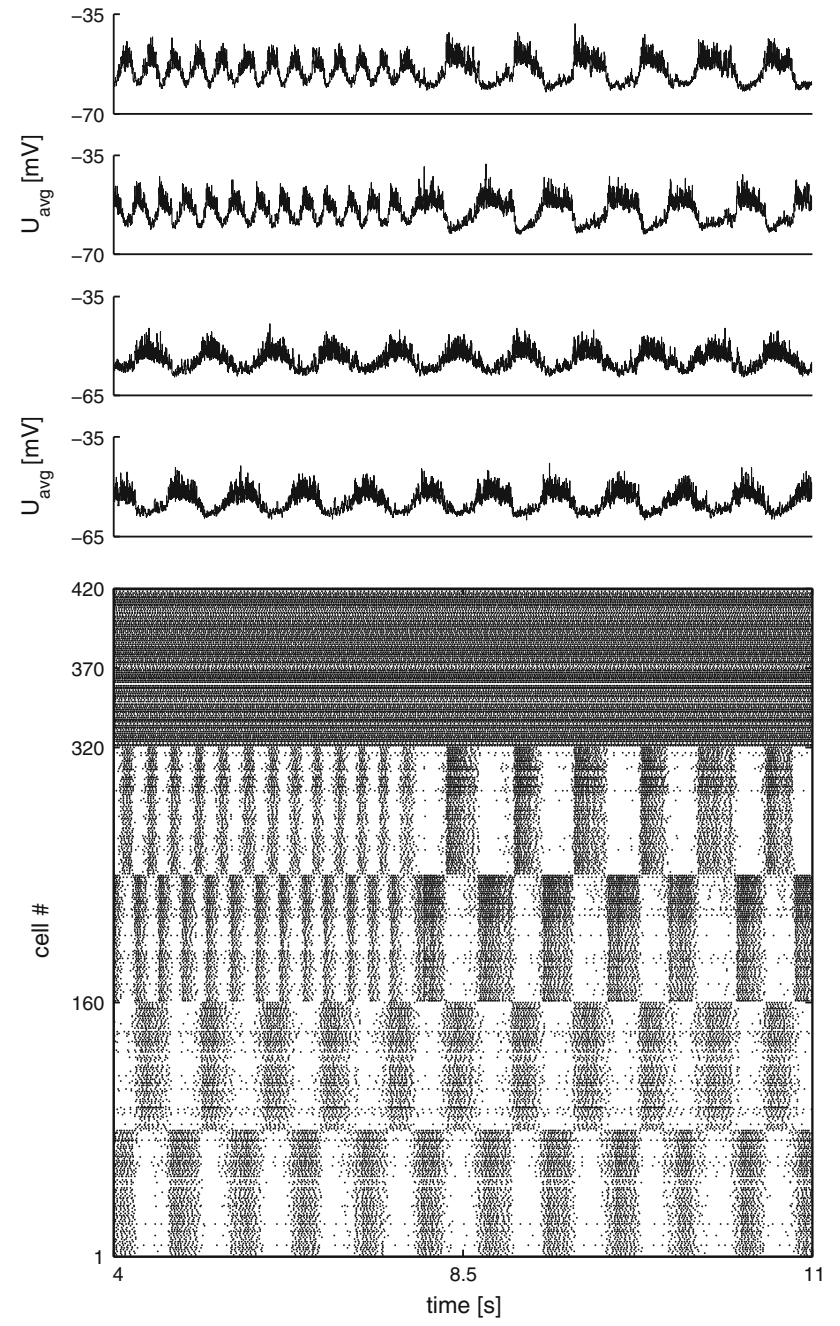

Fig. 12 Two segments with unidirectional coupling from a limb segment to an axial segment. The raster plot shows the activity of two segments activated by their respective driving populations. Cells 1 through 160 represent a segment with parameters set to reproduce slow stepping-like frequencies (here $1.62 \mathrm{~Hz}$ ). Cells 161 through 320 represent a segment with parameters set to reproduce fast swimminglike frequencies (here $3.54 \mathrm{~Hz}$ ). Cells 321 through 420 represent the driving populations. At the $6 \mathrm{~s}$ mark, unidirectional connections from the putative limb segment to the axial segment are turned on and the slow limb frequency is imposed on the fast axial segment. Left limb EINs project to the entire left axial hemisegment. Right limb EINs project to the entire right axial hemisegment

EIN populations to their axial counterparts was sufficient to impose the slow stepping frequencies on the axial segment. Figure 12 shows how the axial segment switched immediately to the slower frequency when coupling was enabled. The obvious interpretation is that this might represent a coupling from limb neuron pools to axial neuron pools since during stepping the low frequencies need to be imposed on the axial networks, which exhibit faster intrinsic frequencies. 


\section{Discussion}

This study shows that a lamprey spinal motor network can be transformed into a corresponding salamander network at the cellular level. This supports the notion that was already expressed by our previous experimental (Ryczko et al. 2010a) and modeling studies [(Ijspeert 2001; Bem et al. 2003; Ijspeert et al. 2005, 2007; Harischandra et al. 2011), for review, see Ijspeert (2008)], namely that the mid-trunk network of the salamander resembles a lamprey-like swimming network and can be modeled accordingly. Comparing data across many species, the high-level similarities in the organization of the axial locomotor CPG across species such as the lamprey [for review, see Grillner (2003)], the zebrafish [for review, see Fetcho and McLean (2010)], the Xenopus embryo [(Kahn and Roberts 1982; Roberts and Tunstall 1990); for review, see Roberts et al. (2010)], reveal that common principles can be traced among vertebrates [for review, see Katz and Harris-Warrick (1999), Orlovsky et al. (1999), Ryczko et al. (2010b)]. However, many different configurations of ionic channels can produce neural oscillators (Prinz et al. 2004). Thus, the present model only represents one possibility for the salamander until it is validated by pre-motoneuron recordings. Nevertheless, we take the fact that the model adequately reproduces a large number of pharmacological experiments (Ryczko et al. 2010a) with a single parameter set (i.e., the model is not retuned from one set of results to the other) as indirect evidence that the underlying rhythm generating composition of ionic channels adequately captures the mechanisms underlying the locomotor CPG oscillations in the salamander to a first approximation. Notably the choice of a NMDA-plateau-based oscillator, that was key to the reproduction of in vitro physiological data, did not impede the emergence of fast, in vivo-like oscillations (see Sect. 4.5).

\subsection{Reproducing physiological data}

The present model reproduces key physiological findings and provides explanations at the cellular level. The effects of blocking glycinergic and AMPA receptors, specific ionic currents $\left(\mathrm{I}_{\mathrm{h}}, \mathrm{I}_{\mathrm{KCaN}}, \mathrm{I}_{\mathrm{NaP}}\right)$ and the relationships between segmental and hemisegmental rhythms are largely reproduced. The main discrepancies are found for segments with blocked AMPA synapses, where oscillations persist, and the relation between segmental and hemisegmental duty cycles (see also Sect. 4.2). The imperfect match of the duty cycle in hemisegments on the other hand-though a priori a tunable parameter-is the result of a trade-off with the reproduction of the pharmacological findings. Increasing the duty cycle is equivalent to weakening the hyperpolarizing components (through modifying inflow and decay rates and the strength of the $\mathrm{K}_{\mathrm{CaNMDA}}$ channel). However after blocking the $\mathrm{K}_{\mathrm{CaN}}$ channel in order to reproduce the apamine results Ryczko et al. (2010a) the weakened remaining hyperpolarizing components can be too weak to stop bursting and tonic activity emerges.

We implemented salamander spinal hemisegments as a sparsely connected population of excitatory neurons. Such a recurrently interconnected network may also account for rhythmogenesis in the lamprey spinal cord (Buchanan and Grillner 1987; Buchanan et al. 1989; Parker and Grillner 2000) and hemicord (Cangiano and Grillner 2003, 2005), as well as in the locomotor network of the Xenopus embryo [Dale and Roberts (1985), Soffe (1989), Li et al. (2006), for review see Roberts and Perrins (1995)]. The model neurons are not intrinsically bursting neurons when current is injected. Rather the minimal pacemaker unit is a set of two neurons coupled with NMDA synapses or an isolated neuron under NMDA bath activation. The neurons possess two fast calcium pools, which extend the frequency range of tonic firing and provide adaptation as well as a slow calcium pool, which drives the $\mathrm{K}_{\mathrm{Ca}}$-channels associated with NMDA synapses. We hypothesize that the synaptic $\mathrm{K}_{\mathrm{Ca}}$-channels are co-localized, or at least functionally coupled, with the NMDA synapse (Faber et al. 2005) and that there is no interference from other calcium pools (Brodin et al. 1991). To the best of our knowledge, this negative feedback between synaptic calcium channels and related $\mathrm{K}_{\mathrm{Ca}}$ channels remains the best model for NMDAinduced TTX-resistant membrane oscillations in the lamprey. It constitutes a long-standing, experimentally supported feature of various lamprey models (Wallén et al. 1992; Huss et al. 2007, 2008). Long period oscillations emerge as a consequence of the interplay between NMDA-induced plateau potentials and $\mathrm{K}_{\mathrm{Ca}}$ channels co-located with the NMDA synapse (see also Sect. 4.4). Among other consequences, this allows for oscillations in isolated hemisegments without reciprocal inhibition. A similar functional coupling has been shown for $\mathrm{K}_{\mathrm{Na}}$ channels that are colocated with AMPA receptors in lamprey spinal neurons; i.e., $\mathrm{Na}^{+}$influx via AMPA receptors activates a slow $\mathrm{K}_{\mathrm{Na}}$ channel that in turn decreases the AMPA-mediated excitation (Nanou and Kyriakatos 2008).

More data at the cellular level are needed to confirm that this negative feedback loop exists in the spinal cord of the salamander. However, several elegant studies showed that the dendritic co-localization of NMDA receptors and $\mathrm{K}_{\mathrm{Ca}}$ channels is responsible for a $\mathrm{Ca}^{2+}$-mediated feedback loop in various brain regions in rodents [(Faber et al. 2005; Ngo-Anh et al. 2005; Bloodgood and Sabatini 2007; Lin et al. 2008; Faber 2010); for review, see Mulholland (2012)]. Note however that the involvement of a NMDA-calcium $\mathrm{K}_{\mathrm{Ca}}$ feedback loop may depend on the type of cell and the type of synaptic connection. For instance in the lamprey, the monosynaptic connection between reticulospinal neurons 
and motoneurons appears not to exhibit a synaptic $\mathrm{K}_{\mathrm{Ca}}$ channel feedback loop (Cangiano et al. 2002).

\subsection{Segmental versus hemisegmental oscillators}

Simulated hemisegments were able to oscillate "autonomously", i.e., without inputs from the contralateral side. This conforms to the reported rhythmogenic capability in vitro of spinal hemicords and hemisegments in the salamander (Ryczko et al. 2009, 2010a) and in the lamprey (Cangiano and Grillner 2003, 2005; Cangiano et al. 2012). Importantly the lamprey hemicord oscillates when electrically stimulated as soon as 2 min after cutting the midline of the spinal cord (Cangiano et al. 2012). Rhythmogenesis thus appears as an intrinsic capability of the hemisegmental networks, rather than an acquired ability due to plasticity of the system after the lesion as suspected by some authors (Hoffman and Parker 2010).

In agreement with Ryczko et al. (2010a) we find that reciprocal inhibitory connections slow down the oscillations in segments compared to hemisegments. A strong reciprocal inhibition will suppress the activity on the contralateral side long enough for the relevant calcium concentration to decay further than in isolated hemisegments, leading to longer bursts after release from inhibition. Ryczko et al. (2010a) reported a segmental duty cycle around $70 \%$. We find such a large duty cycle to be at odds with symmetric reciprocal inhibition, which has to be reasonably strong to slow-down oscillations in segments. In the simulations the inherent symmetry lead to a duty cycle that fluctuated around $50 \%$. The current implementation of inhibitory coupling is probably too rigid, possibly due to the low number of neurons per hemisegment. Another consequence of this is that segmental stability scores are not changing very much. A future iteration of the present model should allow for the possibility of overlap between the decaying phase and the rising phase of oscillations in order to achieve duty cycles above $50 \%$.

Furthermore, we performed our data analysis on the direct output of the EIN subpopulation. The data by Ryczko et al. (2010a) showed recordings of a signal that has been processed by motoneuron pools, whose intrinsic properties may shape the motor output further. Moreover the nature of extracellular recordings introduces a partial decay of the signal (Bédard et al. 2004), and changes in the measured waveform. Our model also lacks propriospinal connections and the co-activation of spinal neurons that are not part of the locomotor-networks by the NMDA bath, which might have distorted the in vitro recordings.

\subsection{Suppressing synaptic transmission}

Glycinergic inhibitory interneurons have been evidenced in the salamander (Jovanovic et al. 1999) and lamprey (McPher- son et al. 1994) spinal cord. Eliminating the inhibition effectively reduced the model to two excitation-coupled hemisegments. In-phase synchronization was facilitated by the excitatory cross-connections. These pathways have been proposed as a simple explanation to this synchronous activity on the basis of the effects of strychnine on spinal networks in the salamander (Ryczko et al. 2010a) and in the lamprey [see, e.g., Cangiano and Grillner (2003)]. These connections did not pose any problem for the remaining results, as in segments the inhibitory, anti-phase coupling is stronger than the excitatory, in-phase coupling. In the lamprey crossed excitatory connections target contralateral motoneurons or inhibitory interneurons, but the commissural projection to contralateral excitatory neurons remains to be demonstrated [(Buchanan 1982; Buchanan and McPherson 1995), see also Mahmood et al. (2009), for review, see Ryczko et al. (2010b)]. Interestingly, the presence of cross-excitatory pathways in the zebrafish (McLean et al. 2007, 2008) and in the limb networks of the rat (Butt and Kiehn 2003) supports the idea that these connections may be a common characteristic of vertebrate locomotor systems. However their role in vivo is poorly understood. In the zebrafish cross-excitatory interneurons are active during slow swimming but not during fast swimming (McLean et al. 2007, 2008). In the salamander two bursts per cycle can be recorded in the tail muscles during stepping (Delvolvé et al. 1997). The second burst occurs synchronously with that of the contralateral muscles. This left-right synchronous muscular pattern could involve cross-excitatory connections (see Bicanski et al. (2012) in the same issue). These might also be used during rhythmic "non locomotor" behaviors (e.g., mating, spawning, etc.) or to increase the flexibility of the left-right coordination pattern (Berg et al. 2007). It cannot be excluded that in the salamander the excitatory cross-connections target contralateral motoneurons, which were not modelled in this study.

In experiments (Ryczko et al. 2010a) the application of 6-cyano-7-nitroquinoxaline-2,3-dione (CNQX) abolished bursting by blocking AMPA synapses. In our simulations this was achieved for hemisegments only. In the segmental case the reciprocal inhibition enforced a rhythm, albeit slightly accelerated, even in the absence of the AMPA synapse. Hemisegments also lack the post inhibitory rebound provided by the h-current after inhibition from the contralateral hemisegment terminates. This discrepancy might be remedied if we assume that CNQX also blocks the transmission from the spinal interneurons to the target motoneuron pools.

\subsection{The role of ionic channels}

Contrary to findings for the lamprey (El Manira et al. 1994), blocking $\mathrm{I}_{\mathrm{KCa}}$ with apamine did not disrupt the ongoing NMDA-induced rhythmic activity in the salamander but rather improved the signal-to-noise ratio in both segments 
and hemisegments (Ryczko et al. 2010a). Ryczko et al. (2010a) hypothesized that similarly to the findings of Faber et al. (2005), blockade of SK channels with apamine can potentiate fast glutamatergic synaptic potentials by removing shunting mediated by SK channels co-localized close to the NMDA synapse. This would in turn increase the signal-to-noise ratio. However, note that apamine most probably affects at least two $\mathrm{K}_{\mathrm{Ca}}$ subtypes. Intracellular recordings of lamprey spinal neurons revealed that apamine slows down NMDA-induced TTX-resistant membrane oscillations (El Manira et al. 1994), suggesting an effect on $\mathrm{K}_{\mathrm{CaNMDA}}$ channels responsible for the termination of depolarized plateaus. In spinal neurons stimulated by current injection, apamine decreases the spike frequency adaptation, which is mediated by $\mathrm{K}_{\mathrm{Ca}}$ channels responsible for the slow afterhyperpolarization (El Manira et al. 1994). The radically different timescales of adaptation (on the order of $100 \mathrm{~ms}$ ) versus NMDA-induced oscillations (several seconds) suggest that these $\mathrm{K}_{\mathrm{Ca}}$ channels are distinct subtypes. Similarly, fast and slow $\mathrm{K}_{\mathrm{Na}}$ channels are present in the lamprey (Nanou and El Manira 2007; Nanou and Kyriakatos 2008; Wallén and Grillner 1997; Wallén et al. 2007; Huss et al. 2007). Reducing the $\mathrm{K}_{\mathrm{CaNMDA}}$ conductance in the present model would trivially slow down oscillations, but blocking it completely would lead to tonic activity. This would not be in line with the effect of apamine reported in the experiments of Ryczko et al. (2010a). Hence, in the model we have restricted the effect of apamine to the adaptation conductance $\mathrm{K}_{\mathrm{CaN}}$. It is a priori conceivable that the $\mathrm{K}_{\mathrm{CaNMDA}}$ channels in the salamander could be apamine-insensitive (Stocker 2004). However if we assume that apamine also blocks the $\mathrm{K}_{\mathrm{CaNMDA}}$ conductance (in addition to the effect on the adaptation channel), then the persistence of oscillations in the experiments by Ryczko and co-workers (2010a) predicts the presence of other inhibitory feedback mechanisms-e.g., slow $\mathrm{K}_{\mathrm{Na}}$ - similarly to the lamprey [see, e.g., Huss et al. (2007)].

Thus, in this model the increase in signal-to-noise ratio after in simulated application of apamine is achieved through the block of $\mathrm{I}_{\mathrm{KCaN}}$ channels. This blockade brings previously spiking neurons, or neurons that fired short irregular bursts into the long period bursting regime. The simulation results correspond to the experimentally observed effect of apamine concerning the stability of the rhythm in hemisegments. For segments the stability did not change markedly since the strong reciprocal inhibition enforced stable segmental oscillations already under control conditions. The effect of apamine in the model can also account for cases where apamine led to the emergence of oscillations from NMDAinduced tonic discharges observed in vitro (Ryczko et al. 2010a). However, the duty cycle did not decrease when compared to hemisegments under control conditions, contrary to what was observed by Ryczko et al. (2010a). Possibly $\mathrm{I}_{\mathrm{KCaN}}$ channels susceptible to endogenous release of neuromodulators determine the number of neurons in the bursting regime and the intrinsic frequency (Grashow et al. 2009). Chevallier et al. (2006) demonstrated that a concentration of apamine in the same range as the one used by Ryczko et al. (2010a) blocks the medium afterhyperpolarization (mAHP) in salamander hindlimb motoneurons.

Though there is some controversy over the selectivity of the blocker ZD 7288 toward $\mathrm{I}_{\mathrm{h}}$ channels (Wang et al. 2011), our results are in agreement with the interpretation that blocking $\mathrm{I}_{\mathrm{h}}$ slowed down the oscillations by prolonging the recovery period, albeit only mildly, especially for segments. This is consistent with $\mathrm{I}_{\mathrm{h}}$ being a hyperpolarization activated, depolarizing current. This result and the fact that $\mathrm{I}_{\mathrm{h}}$ is sensitive to muscarinic (Chevallier et al. 2006) and serotonergic modulation (Pape 1996; Kiehn et al. 2000) suggest a role in adjusting the cycle duration and duty cycle.

In further agreement with the experimental data (Ryczko et al. 2010a), blocking the Nap current abolishes activity. In our model the NMDA-induced depolarization is insufficient to induce bursting if the background elevation of the membrane potential and the increased excitability due to $\mathrm{I}_{\mathrm{NaP}}$ is removed. This is in accordance with the initial observation that $\mathrm{I}_{\mathrm{NaP}}$ controls of the excitability at subthreshold potential [Llinás 1980; Stafstrom et al. 1982; for review see Llinás (1988)]. As such, $\mathrm{I}_{\mathrm{NaP}}$ can control cellular rhythmic properties by triggering burst initiation. Such a role for $\mathrm{I}_{\mathrm{NaP}}$ has been modeled accordingly for the respiratory system (Butera and Rinzel 1999; Butera et al. 1999) and for the locomotor system (Rybak et al. 2006; Daun et al. 2009). Its involvement in rhythmogenesis has been observed experimentally in the limb locomotor networks of the neonatal rat (Tazerart et al. 2007) and mouse (Zhong et al. 2007) and in the axial locomotor network of the salamander (Ryczko et al. 2010a). Future experiments must determine whether salamander CPG neurons exhibit more than one type of sodium channel as in our model, or just one sodium channel that is riluzole-sensitive.

\subsection{Fast rhythms}

In general, the frequency range of segments and hemisegments under NMDA-stimulation is extremely limited for an isolated sample when compared to the variability among samples (Delvolvé et al. 1999; Ryczko et al. 2010a). The present model offers a tentative explanation of how longperiod fictive locomotion rhythms and in vivo activity might be related in the salamander. Long-period rhythms are dominated by the CaNMDA subsystem, whereas it constitutes only one contribution to burst termination in vivo. In the lamprey, a similar distinction between the mechanisms underlying fast and slow rhythms has been discussed by Cangiano and Grillner (2003). 
In this study we focused on a basic, biologically plausible descending drive simulating reticulospinal (RS) neurons. In lampreys the background excitation of the spinal network is controlled by descending projections from the RS neurons (Buchanan and Grillner 1987; Brodin et al. 1988; Ohta and Grillner 1989), that are driven by supraspinal locomotor centers, that include the mesencephalic locomotor region (henceforth MLR) (Sirota et al. 2000; Brocard et al. 2010) and diencephalic locomotor region (El Manira et al. 1997). In salamanders, the MLR controls the activity of the locomotor network (Cabelguen et al. 2003), most probably via a direct connection onto glutamatergic reticulospinal neurons (Chevallier et al. 2004). This is consistent with the observations in the salamander that neurons in the reticular region are activated when the MLR is stimulated (Bar-Gad et al. 1999) or during in vivo locomotion (Hubbard et al. 2010). To investigate the ability of descending drives to extend the frequency range of segmental networks we added a separate group of RS neurons as a driving population. Importantly all previous results (reproducing the physiological data) were conserved since the segmental model neurons remained unchanged. With this addition the model is capable of covering a large fraction of the in vivo frequency range corresponding to swimming frequencies andwith minor adjustments-also the lower stepping frequency range. These adjustments were limited to the reduction of the $\mathrm{I}_{\mathrm{KCaN}}$ conductance by roughly half, and a minor change in calcium inflow and decay rates. Thus a few modifications at the cellular level allow for networks with different intrinsic frequency ranges. The most stable range of frequencies corresponding to both in vivo swimming and stepping were obtained by scaling the strength of the $\mathrm{K}_{\mathrm{CaN}}$ current. A weaker $\mathrm{K}_{\mathrm{CaN}}$ current yielded lower frequencies.

Several mechanisms based on the scaling of the $\mathrm{K}_{\mathrm{CaN}}$ conductance could control locomotor frequency. Neuromodulation of the $\mathrm{I}_{\mathrm{KCa}}$ conductance of the same neuron pool constitutes one possibility. In the salamander descending and intraspinal serotoninergic neurons are present, and serotonin decreases the locomotor frequency when bath-applied on a brainstem-spinal cord preparation (Jovanovic et al. 1996; Branchereau et al. 2000). Our model would predict that serotonin would decrease in the $\mathrm{K}_{\mathrm{CaN}}$ conductance, as observed in the lamprey (Matsushima and Grillner 1992). More neurons with a broader spectrum of $\mathrm{Ca}_{\mathrm{N}}$ inflow and decay values and $\mathrm{K}_{\mathrm{CaN}}$ conductance strengths might reduce the need for active neuromodulation. The interburst interval would then be mainly dictated by the slow afterhyperpolarization of neurons, synchronized through their mutual excitation (Cangiano and Grillner 2003).

Alternatively a differential recruitment of pools of interneurons with different sets of $\mathrm{K}_{\mathrm{CaN}}$ conductances could cover the in vivo frequency range. The recruitment threshold could rely on the input resistance of the different pools as demonstrated for motoneurons in the larval zebrafish (McLean et al. 2007). Alternatively it could be determined by the interplay between the intrinsic properties and the strength of the descending synaptic inputs as reported in the juvenile/adult zebrafish (Gabriel et al. 2010). Intracellular recordings of spinal interneurons are needed to test whether the active set of spinal interneurons progressively shifts as the locomotor frequency increases, as observed in the zebrafish (McLean et al. 2008). The observation that the spinal cord of salamanders also shares organizational principles with these animals (Nieuwenhuys et al. 1998; Harper and Roberts 1993; reviewed in Ryczko et al. 2010b) suggests that these might serve similarly to the lamprey in guiding further investigations into the salamander locomotor system.

Scaling the strength of the descending NMDA synapse allowed for frequency ranges comparable to those obtained by scaling the $\mathrm{K}_{\mathrm{CaN}}$ conductance. However in the stepping frequency range the variability of the measured cycle duration increased in this case, because the recurrent connectivity in the EIN network coupled with an unfavorable random seed could occasionally enforce NMDA dominated oscillations (however, see Sect. 4.7). This is most likely due to the limited number of neurons and the neurons being all endowed with similar properties. The absence of sensory feedback is another major factor that increases the variability in all conditions (and possibly limits the range) of our simulated in vivo like oscillations. In the lamprey, intraspinal mechanosensitive neurons ("edge cells") provide movementrelated feedback input to the swimming CPG and contribute to burst termination (Grillner et al. 1982, 1984). In salamanders, intraspinal marginal neurons distributed all along the ventrolateral edge of the spinal cord (Schroeder and Egar 1990) show strong similarities with the edge cells of lampreys, but their functional role remains to be demonstrated.

\subsection{A dynamically adjusting CPG network}

The modulatory effects of the $\mathrm{I}_{\mathrm{KCaN}}$ conductance and NDMA synapse also suggest that differential recruitment of different RS populations could determine, through the distribution of their descending synaptic properties, the frequency of the locomotor CPG. Interestingly in the larval zebrafish RS neurons are recruited dorso-ventrally as the swimming frequency increases (Kinkhabwala et al. 2011). In the larval lamprey RS neurons from the middle and the posterior rhombencephalic reticular nuclei are differentially recruited according to the swimming frequency controlled by stimulation of the MLR (Brocard and Dubuc 2003). These observations are compatible with the picture of a locomotor CPG in which active sets interneurons and motoneurons dynamically change with speed and with the locomotor mode, as observed both in the zebrafish (Ritter et al. 2001; Kimura et al. 2006; Bhatt et al. 2007; McLean et al. 2007, 2008; Satou et al. 2009; 
Gabriel et al. 2010; Liao and Fetcho 2009; for review, see Fetcho and McLean 2010) and in the Xenopus tadpole ( $\mathrm{Li}$ et al. 2007; for review, see Roberts et al. (2010)). Different sets of descending projections, due to the recruitment of different RS neurons with increasing drive from the MLR, might be part of this dynamic reorganization of the locomotor CPG.

During locomotion, RS neurons further exhibit some rhythmicity, which is most likely due to ascending feedback (Dubuc and Grillner 1989; Vinay and Grillner 1993; Einum 2004; Einum and Buchanan 2006a,b; Antri et al. 2009; Buchanan 2011). Ascending feedback might play a crucial role in shaping segmental rhythms in the salamander as well. However, the exact interplay of ascending and descending pathways found within the salamander spinal cord (Davis et al. 1989; Munoz et al. 1997) remains to be determined and was not within the scope of this study.

\subsection{NMDA dynamics}

One potential discrepancy with experimental data is that in the present model all frequencies can emerge at similar RS drives, when the $\mathrm{I}_{\mathrm{KCaN}}$ conductance or the NMDA synapse are scaled. Cabelguen et al. (2003) have shown that decerebrated, semi-intact salamanders exhibit a gait transition from stepping to swimming as the stimulation of the MLR is increased. In the lamprey the locomotor frequency positively correlates with the spiking frequency of RS neurons, which relay the MLR command to the locomotor networks (Brocard et al. 2010). Whether or not this holds true for the salamander as well must be determined by future experiments. One possible solution could involve a differential recruitment of RS neurons. At higher locomotor frequencies, previously active RS neurons might deactivate while another population of RS neurons activate, implementing a progressive shift in the currently active RS descending drive. Alternatively differential recruitment may occur in the rhythm-generating network of pre-motoneurons as mentioned above for the zebrafish (McLean et al. 2008). Another possibility to restore the positive correlation between injected current into the MLR, RS frequency and the locomotor frequency could involve a different mixture of descending synapses (NMDA versus AMPA) and a more sophisticated synapse model, including a saturation mechanism (Hellgren et al. 1992; Tråvén et al. 1993).

The NMDA dynamics, which are crucial for the reproduction of experimental data presented herein, remain the best model for TTX-resistant membrane oscillations in spinal interneurons of the lamprey (Wallén et al. 1992; Huss et al. 2007, 2008). We show that if the calcium inflow rate scales non-linearly with the NMDA stimulation, this can also restore a positive correlation between the spiking activity of the RS neurons and locomotor fre- quency. This increasing calcium inflow is reminiscent of the recruitment of added (non-synaptic) calcium channels

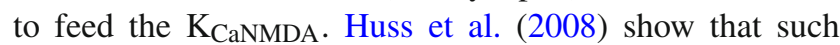
an addition of a generic calcium current to their minimal model of NMDA-induced TTX-resistant membrane oscillations restored a positive correlation between increasing stimulation and the frequency of the oscillations produced by their model. These generic calcium channels could represent regular dendritic membrane channels in the vicinity of the NMDA synapse (Bloodgood and Sabatini 2007).

\subsection{Coupling slow and fast oscillators}

Using the present implementation of descending drive the model further allows for the study of coupling relations between networks that have different intrinsic frequencies as has been observed for the salamander (Ijspeert et al. 2007). We presented an example where slow stepping like frequencies were imposed on a network with faster intrinsic frequencies, corresponding to in vivo swimming activity. Such a mechanism might be necessary in the gait transition from swimming to stepping in salamanders (Cabelguen et al. 2003; Ijspeert et al. 2007). During stepping the axial segments oscillate with slow frequencies. If the imposed frequency can be passed down the axial network, then an axial segment with a fast intrinsic frequency range can readily participate in stepping movement. During swimming (at higher RS drives) the limb networks would generate tonic activity, which would manifest itself as added excitation to the axial network. Interestingly experiments on isolated spinal cords have shown that the axial CPG can produce traveling waves even when the limb CPGs are rhythmically active (Ryczko et al. 2009). This is consistent with a coupling of limb oscillators mainly to the nearest axial oscillators (i.e., local coupling, as opposed to global coupling to large parts of the axis, see Ijspeert et al. 2005). In this study we used a simple coupling mechanism, which relies only on a sparse, uni-directional coupling from excitatory limb CPG neurons to axial hemisegments. Paired cellular recordings might be used to investigate the nature of the coupling between limb and axial networks.

Note that the RS neuron population that we used to drive the segmental network may also account for other descending or sensory neurons that could be activated during the various aquatic and terrestrial locomotor behaviors exhibited by salamanders in vivo (for review see Cabelguen et al. 2010, Bicanski et al. 2012). Similar setups might be used to study in more detail how sensory feedback and descending drive and ascending feedback shape the couplings between spinal oscillators. 


\subsection{Conclusion}

This study shows that a lamprey-like segmental network (using a modified lamprey neuron model) can be transformed into a salamander network, which conforms to experimental data. It gives further credence to the notion of phylogenetic conservatism for the vertebrate nervous system (StephensonJones et al. 2011). Naturally, we do not suggest that the present model reflects all salamander locomotor CPG properties and many details await further investigation. In particular the model must now be tested by pre-motoneuron recordings. Indirect validation in form of pharmacological experiments can only take us so far. From a modeling point of view an important extension of the present work would be to introduce more neurons with variable properties (e.g., size, input resistance, conductances, etc.) and possibly a more sophisticated synapse model.

Acknowledgments A. B. receives financial supported from the Swiss initiative in systems biology: SystemsX.ch. J.-M.C. receives grants from the European Community (LAMPETRA Grant: FP7-ICT-20071-216100) and the Fondation pour la Recherche Médicale (DBC 20101021008). D. R. receives salary support from the Groupe de Recherche sur le Système Nerveux Central (GRSNC) and the Fonds de la Recherche en Santé du Québec (FRSQ). A. J. I. acknowledges support from the European Community (LAMPETRA Grant: FP7-ICT2007-1-216100). A. B. acknowledges Jeremie Knüsel for critical comments on the manuscript and Daniele Colangelo for IT support; further more Richard Naud, Skander Mensi, Christian Pozzorini and Andrea Prunotto for fruitful discussions.

\section{Appendix: Equations and parameters}

Neurons are modeled as standard Hodgkin-Huxley neurons (Hodgkin and Huxley 1952) with three electrically coupled compartments, one for the soma, one for the dendrites and an initial compartment reminiscent of the axon hillock in order to transform spike-like membrane oscillations into full amplitude action potentials. The following equation governs the membrane potential $\mathrm{U}$ of individual compartments

$C \frac{\mathrm{d} U}{\mathrm{~d} t}=\sum_{i}\left(U_{i}-U\right) g_{\text {core }}+\sum_{j} I_{j}+I_{\text {leak }}$,

where the first sum is taken over the adjacent compartments. The sum over $j$ indicates summation over compartmental currents. $I_{\text {leak }}$ is the leak current. $C$ represents the capacitance and $g_{\text {core }}$ the electrical coupling to the adjacent compartments. The currents are modeled with the standard HodgkinHuxley equations of the type

$I_{j}=g_{j} p^{a} q^{b}\left(U_{i}-E_{\mathrm{rev}}\right)$

Here $g_{j}$ is the conductance of the ionic channel, $p^{a}$ and $q^{b}$ its activation and inactivation variables with their respective exponents and $E_{\text {rev }}$ the reversal potential of the charge carri- ers in question. The activation and inactivation variables are described either in terms of opening and closing rates $\alpha$ and $\beta$. E.g.,

$\frac{\mathrm{d} p}{\mathrm{~d} t}=\alpha_{\mathrm{p}}(U)(1-p)-\beta_{\mathrm{p}}(U) p$,

or in terms time constants $\tau_{\mathrm{p}}$ and asymptotic values $p_{\text {inf }}$

$\frac{\mathrm{d} p}{\mathrm{~d} t}=\frac{p_{\text {inf }}-p}{\tau_{\mathrm{p}}}$

The equations for calculating $\alpha$ and $\beta$ are given below. Channels parameters are summarized in Table 2. For calcium concentration-dependent currents the activation is modeled with a concentration-dependent variable $z$ for each calcium pool $\left(\mathrm{Ca}_{\mathrm{N}}, \mathrm{Ca}_{\mathrm{L}}, \mathrm{Ca}_{\mathrm{NMDA}}\right.$ synapse)

$z=\frac{[\mathrm{Ca}]}{B_{z}}$,

where $B_{z}$ is a pool-specific parameter (modified from Huss et al. 2007). The concentrations are modeled with an equation of the type

$\frac{\mathrm{d}[\mathrm{Ca}]}{\mathrm{d} t}=\mathrm{AI}-\mathrm{B}[\mathrm{Ca}]$,

where the parameters $A$ and $B$ determine the calcium inflow and decay, respectively. When the calcium inflow scaled with strength of the descending drive the following heuristic scaling factor was used

$A\left(f_{\mathrm{RS}}\right)=\frac{f_{\mathrm{RS}}^{2.4}}{f_{\mathrm{RS}-\text { base }}^{2.4}}$

where $f_{\mathrm{RS}}$ is the average spiking frequency of the RS population and $f_{\mathrm{RS} \text {-base }}$ the reference value.

Synaptic communication is implemented as follows. Upon detection of a spike the synaptic conductance is raised instantaneously to the value given in Table 1 and then decays exponentially (cf. Table 1). The electrotonic properties of the dendrites attenuate an AMPA EPSP elicited in the dendrite by roughly $40 \%$ in the soma. (EPSP amplitude $0.74 \mathrm{mV}$ in dendrite vs. $0.45 \mathrm{mV}$ in soma).

Channel kinetics were computed with the following equations. Channel parameters (cf. Table 2) are linked to their respective equations by the numbers in their subscripts, which indicate the equation number. Here, $a(U)$ is a placeholder for the calculated quantity.

$$
\begin{aligned}
& a(U)=\frac{A(U-B)}{1-\exp ((B-U) / C)} \\
& a(U)=\frac{A(B-U)}{1-\exp ((U-B) / C)} \\
& a(U)=\frac{A}{1+\exp ((B-U) / C)}
\end{aligned}
$$


$a(U)=A \exp ((U-B) / C)$

$a(U)=A \exp (-(U-B) / C)$

$a(U)=\frac{1}{1+\exp ((U-B) / C)}$

$a(U)=\frac{1}{1+\exp ((B-U) / C)}$

$a(U)=A+B * \exp \left(-(C-U)^{2} / D^{2}\right)$

The coupled membrane potential equation was solved using the reverse Euler method [Dayan and Abbott (2001) and references therein] while the simpler equations are solved with a Runge-Kutta 4 implementation.

\section{References}

Antri M, Fénelon K, Dubuc R (2009) The contribution of synaptic inputs to sustained depolarizations in reticulospinal neurons. J Neurosci 29:1140-1151

Bar-Gad I, Kagan I, Shik ML (1999) Behavior of hindbrain neurons during the transition from rest to evoked locomotion in a newt. Prog Brain Res 123:285-294

Bem T, Cabelguen J-M, Ekeberg Ö, From swimming to walking: a single basic network for two different behaviors. Biol Cybern 88:7990.

Berg RW, Alaburda A, Hounsgaard J (2007) Balanced inhibition and excitation drive spike activity in spinal half-centers. Science 315:390-393

Bédard C, Kröger H, Destexhe A (2004) Modeling extracellular field potentials and the frequency-filtering properties of extracellular space. Biophys J 86:1829-1842

Bicanski A, Ryczko D, Knuesel J, Harischandra N, Charrier V, Ekeberg Ö, Cabelguen J-M, Ijspeert AJ (2012) Decoding the mechanisms of gait generation in salamanders by combining neurobiology, modeling and robotics. Biol Cybern. doi:10.1007/s00422-012-543-1

Bischofberger J, Schild D (1995) Different spatial patterns of [Ca2+] increase caused by $\mathrm{N}$ - and L-type $\mathrm{Ca} 2+$ channel activation in frog olfactory bulb neurones. J Physiol 487(Pt 2):305-317

Bhatt DH, McLean DL, Hale ME, Fetcho JR (2007) Grading movement strength by changes in firing intensity versus recruitment of spinal interneurons. Neuron 53:91-102

Bloodgood BL, Sabatini BL (2007) Nonlinear regulation of unitary synaptic signals by $\mathrm{CaV} 2.3$ voltage-sensitive calcium channels located in dendritic spines. Neuron 53:249-260

Branchereau P, Rodriguez JJ, Delvolvé I, Abrous DN, Le Moal M, Cabelguen JM (2000) Serotonergic systems in the spinal cord of the amphibian urodele Pleurodeles waltl. J Comp Neurol 419:49-60

Brocard F, Ryczko D, Fénelon K, Hatem R, Gonzales D, Auclair F, Dubuc R (2010) The transformation of a unilateral locomotor command into a symmetrical bilateral activation in the brainstem. J Neurosci 30:523-533

Brocard F, Dubuc R (2003) Differential contribution of reticulospinal cells to the control of locomotion induced by the mesencephalic locomotor region. J Neurophysiol 90:1714-1727

Brodin L, Grillner S, Dubuc R, Ohta Y, Kasicki S, Hökfelt T (1988) Reticulospinal neurons in lamprey: transmitters, synaptic interactions and their role during locomotion. Arch Ital Biol 126:317345
Brodin L, Traven H, Lansner A (1991) Computer simulations of Nmethyl-D-aspartate receptor-induced membrane properties in a neuron model. J Neurophysiol 66:473-484

Buchanan J (1982) Identification of interneurons with contralateral, caudal axons in the lamprey spinal cord: synaptic interactions and morphology. J Neurophysiol. 47:5

Buchanan JT, Grillner S, Cullheim S, Risling M (1989) Identification of excitatory inter-neurons contributing to generation of locomotion in lamprey: structure, pharmacology, and function. J Neurophysiol 62:59-69

Buchanan JT, Grillner S (1987) Newly identified "glutamate interneurons" and their role in locomotion in the lamprey spinal cord. Science 236:312-314

Buchanan JT, McPherson DR (1995) The neuronal network for locomotion in the lamprey spinal cord: evidence for the involvement of commissural interneurons. J Physiol Paris 89(4-6):221-233

Buchanan JT (2011) Spinal locomotor inputs to individually identified reticulospinal neurons in the lamprey. J Neurophysiol 106:23462357

Butera R, Rinzel J (1999) Models of respiratory rhythm generation in the pre-Bötzinger complex. I. Bursting pacemaker neurons. J Neurophysiol 82:382-397

Butera RJ, Rinzel J, Smith JC (1999) Models of respiratory rhythm generation in the pre-Bötzinger complex. II. Populations of coupled pacemaker neurons. J Neurophysiol 82:398-415

Butt SJ, Kiehn O (2003) Functional identification of interneurons responsible for left-right coordination of hindlimbs in mammals. Neuron 38:953-963

Cabelguen J-M, Bourcier-Lucas C, Dubuc R (2003) Bimodal locomotion elicited by electrical stimulation of the midbrain in the salamander Notophthalmus viridescens. J Neurosci 23:2434-2439

Cabelguen J-M, Ijspeert A, Lamarque S, Ryczko D (2010) Axial dynamics during locomotion in vertebrates: lesson from the salamander. Prog Brain Res 187:149-162

Cangiano L, Wallén P, Grillner S (2002) Role of apamin-sensitive KCa channels for reticulospinal synaptic transmission to motoneuron and for the after hyperpolarization. J Neurophysiol 88:289-299

Cangiano L, Grillner S (2003) Fast and slow locomotor burst generation in the hemispinal cord of the lamprey. J Neurophysiol 89(6):29312942

Cangiano L, Grillner S (2005) Mechanisms of rhythm generation in a spinal locomotor network deprived of crossed connections: the lamprey hemicord. J Neurosci 25:923-935

Cangiano L, Hill RH, Grillner S (2012) The hemisegmental locomotor network revisited. Neuroscience 210:33-37

Cheng J, Jovanovic K, Aoyagi Y, Bennett DJ, Han Y, Stein RB (2002) Differential distribution of interneurons in the neural networks that control walking in the mudpuppy (Necturus maculatus) spinal cord. Exp Brain Res 145:190-198

Chevallier S, Jan Ijspeert A, Ryczko D, Nagy F, Cabelguen J-M (2008a) Organisation of the spinal central pattern generators for locomotion in the salamander: Biology and modelling. Brain Res Rev 57:147161

Chevallier S, Landry M, Nagy F, Cabelguen J-M (2004) Recovery of bimodal locomotion in the spinal-transected salamander, Pleurodeles waltlii. Eur J Neurosci 20:1995-2007

Chevallier S, Nagy F, Cabelguen J-M (2006) Cholinergic control of excitability of spinal motoneurones in the salamander. J Physiol 570:525-540

Chevallier S, Nagy F, Cabelguen J-M (2008b) Muscarinic control of the excitability of hindlimb motoneurons in chronic spinal-transected salamanders. Eur J Neurosci 28:2243-2253

Cohen AH, Rossignol S, Grillner S (1988) Neural control of rhythmic movements in vertebrates. Wiley, New York 1 
Dale N, Roberts A (1985) Dual-component amino-acid-mediated synaptic potentials - excitatory drive for swimming in xenopus embryos. J Physiol 363:35-59

Daun S, Rubin JE, Rybak IA (2009) Control of oscillation periods and phase durations in half-center central pattern generators: a comparative mechanistic analysis. J Comput Neurosci 27:3-36

Davis BM, Duffy MT, Simpson SB (1989) Bulbospinal and intraspinal connections in normal and regenerated salamander spinal cord. Exp Neurol 103:41-51

Dayan P, Abbott LF (2001) Theoretical neuroscience: computational and mathematical modeling of neural systems. MIT Press, Cambridge

Delvolvé I, Bem T, Cabelguen JM (1997) Epaxial and limb muscle activity during swimming and terrestrial stepping in the adult newt, Pleurodeles waltl. J Neurophysiol 78:638-650

Delvolvé I, Branchereau P, Dubuc R, Cabelguen JM (1999) Fictive rhythmic motor patterns induced by NMDA in an in vitro brain stem-spinal cord preparation from an adult urodele. J Neurophysiol 82:1074-1077

Dubuc R, Grillner S (1989) The role of spinal-cord inputs in modulating the activity of reticulospinal neurons during fictive locomotion in the lamprey. Brain Res 483:196-200

Einum J (2004) Reticulospinal neurons receive direct spinobulbar inputs during locomotor activity in lamprey. J Neurophysiol 92:1384-1390

Einum JF, Buchanan JT (2006a) Membrane potential oscillations in reticulospinal and spinobulbar neurons during locomotor activity. J Neurophysiol 94:273-281

Einum JF, Buchanan JT (2006b) Spinobulbar neurons in lamprey: cellular properties and synaptic interactions. J Neurophysiol 96:20422055

Ekeberg Ö, Wallén P, Lansner A, Tråvén H (1991) A computer based model for realistic simulations of neural networks. Biol Cybern 65:81-90

Ekeberg Ö (1993) A combined neuronal and mechanical model of fish swimming. Biol Cybern 69:363-374

El Manira A, Tegnér J, Grillner S (1994) Calcium-dependent potassium channels play a critical role for burst termination in the locomotor network in lamprey. J Neurophys 72(4):1852-1861

El Manira A, Pombal M, Grillner S (1997) Diencephalic projection to reticulospinal neurons involved in the initiation of locomotion in adult lampreys Lampetra fluviatilis. J Comp Neurol 389:603-616

Faber ESL, Delaney AJ, Sah P (2005) SK channels regulate excitatory synaptic transmission and plasticity in the lateral amygdala. Nat Neurosci 8:635-641

Faber ESL (2010) Functional interplay between NMDA receptors, SK channels and voltage-gated $\mathrm{Ca} 2+$ channels regulates synaptic excitability in the medial prefrontal cortex. J Physiol 588:1281-1292

Falgairolle M, de Seze M, Juvin L, Morin D, Cazalets J-R (2006) Coordinated network functioning in the spinal cord: an evolutionary perspective. J Physiol Paris 100:304-316

Fetcho JR, McLean DL (2010) Some principles of organization of spinal neurons underlying locomotion in zebrafish and their implications. Ann NY Acad Sci 1198:94-104

Frolich L, Biewener A (1992) Kinematic and electromyographic analysis of the function-al-role of the body axis during terrestrial and aquatic locomotion in the salamander Ambystoma tigrinum. J Exp Biol 162:107-130

Gabriel JP, Ausborn J, Ampatzis K, Mahmood R, Eklöf-Ljunggren E, El Manira A (2010) Principles governing recruitment of motoneurons during swimming in zebrafish. Nature 14:93-99

Gao KQ, Shubin NH (2001) Late Jurassic salamanders from northern China. Nature 410:574-577

Gerstner W, Kistler W (2002) Spiking neuron models. Cambridge University Press, Cambridge
Grashow R, Brookings T, Marder E (2009) Reliable neuromodulation from circuits with variable underlying structure. Proc Natl Acad Sci 106:11742-11746

Grillner S, McClellan A, Sigvardt K (1982) Mechanosensitive neurons in the spinal-cord of the lamprey. Brain Res 235-1:169-173

Grillner S, Wallén P (1985) Central pattern generators for locomotion, with special reference to vertebrates. Annu Rev Neurosci. 8:233261

Grillner S, Williams T, Lagerback PA (1984) The edge cell, a possible intraspinal mechanoreceptor. Science 223-4635:500-503

Grillner S, Buchanan JT, Lansner A (1988) Simulation of the segmental burst generating network for locomotion in lamprey. Neurosci Lett $89: 31-35$

Grillner S (2003) The motor infrastructure: from ion channels to neuronal networks. Nat Rev Neurosci 4:573-586

Grillner S (2006) Biological pattern generation: the cellular and computational logic of networks in motion. Neuron 52:751-766

Harper CE, Roberts A (1993) Spinal cord neuron classes in embryos of the smooth newt Triturus vulgaris: a horseradish peroxidase and immunocytochemical study. Philos Trans R Soc Lond Ser B 340(1291): 141-160

Harischandra N, Knuesel J, Kozlov A, Bicanski A, Cabelguen JM, Ijspeert AJ, Ekeberg Ö (2011) Sensory feedback plays a significant role in generating walking gait and in gait transition in salamanders: a simulation study. Front Neurorobot 5:3

Hellgren J, Grillner S, Lansner A (1992) Computer simulation of the segmental neural network generating locomotion in lamprey by using populations of network interneurons. Biol Cybern 68:1-13

Hoffman N, Parker D (2010) Lesioning alters functional properties in isolated spinal cord hemisegmental networks. Neuroscience 168(3):732-743.

Hodgkin AL, Huxley AF (1952) A quantitative description of membrane current and its application to conduction and excitation in nerve. $\mathrm{J}$ Physiol 117:500-544

Hubbard CS, Dolence EK, Rose JD (2010) Brainstem reticulospinal neurons are targets for corticotropin-releasing factor-induced locomotion in roughskin newts. Horm Behav 57:237-246

Huss M, Lansner A, Wallén P, el Manira A, Grillner S, Kotaleski JH (2007) Roles of ionic currents in lamprey CPG neurons: a modeling study. J Neurophysiol 97:2696-2711

Huss M, Wang D, Trané C, Wikström M, Hellgren Kotaleski J (2008) An experimentally constrained computational model of NMDA oscillations in lamprey CPG neurons. J Comput Neurosci 25:108-121

Ijspeert AJ (2001) A connectionist central pattern generator for the aquatic and terrestrial gaits of a simulated salamander. Biol Cybern 84:331-348

Ijspeert AJ, Crespi A, Cabelguen J-M (2005) Simulation and robotics studies of sala-mander locomotion: applying neurobiological principles to the control of locomotion in robots. Neuroinformatics 3:171195

Ijspeert AJ, Crespi A, Ryczko D, Cabelguen J-M (2007) From swimming to walking with a salamander robot driven by a spinal cord model. Science 315:1416-1420

Ijspeert AJ (2008) Central pattern generators for locomotion control in animals and robots: a review. Neural Netw 21:642-653

Izhikevich EM (2007) Dynamical systems in neuroscience. MIT Press, Cambridge

Jovanovic K, Petrov T, Greer JJ, Stein RB (1996) Serotonergic modulation of the mudpuppy (Necturus maculatus) locomotor pattern in vitro. Exp Brain Res 111:57-67

Jovanovic K, Petrov T, Stein RB (1999) Effects of inhibitory neurotransmitters on the mudpuppy (Necturus maculatus) locomotor pattern in vitro. Exp Brain Res 129:172-184 
Jovanovic K, Burke RE (2004) Morphology of brachial segments in mudpuppy (Necturus maculatus) spinal cord studied with confocal and electron microscopy. J Comp Neurol 471:361-385

Kahn J, Roberts A (1982) Experiments on the central pattern generator for swimming in amphibian embryos. Philos Trans R Soc Lond B Biol Sci 296: 229-243

Katz P, Harris-Warrick R (1999) The evolution of neuronal circuits underlying species-specific behavior. Curr Opin Neurobiol 9:628633

Kiehn O, Kjaerulff O, Tresch MC, Harris-Warrick RM (2000) Contributions of intrinsic motor neuron properties to the production of rhythmic motor output in the mammalian spinal cord. Brain Res Bull 53:649-659

Kimura Y, Okamura Y, Higashijima S (2006) alx, a zebrafish homolog of Chx10, marks ipsilateral descending excitatory interneurons that participate in the regulation of spinal locomotor circuits. J Neurosci 26:5684-5697

Kinkhabwala A, Riley M, Koyama M, Monen J, Satou C, Kimura Y, Higashijima S-I, Fetcho J (2011) A structural and functional ground plan for neurons in the hindbrain of zebrafish. Proc Natl Acad Sci 108:1164-1169

Kotaleski JH, Grillner S, Lansner A (1999a) Neural mechanisms potentially contributing to the intersegmental phase lag in lamprey. I. Segmental oscillations dependent on reciprocal inhibition. Biol Cybern 81:317-330

Kotaleski JH, Lansner A, Grillner S (1999b) Neural mechanisms potentially contributing to the intersegmental phase lag in lamprey. II. Hemisegmental oscillations produced by mutually coupled excitatory neurons. Biol Cybern 81:299-315

Kozlov A, Huss M, Lansner A, Kotaleski JH, Grillner S (2009) Simple cellular and network control principles govern complex patterns of motor behavior. Proc Natl Acad Sci 106:20027-20032

Kozlov AK, Lansner A, Grillner S, Kotaleski JH (2007) A hemicord locomotor network of excitatory interneurons: a simulation study. Biol Cybern 96:229-243

Li W, Soffe S, Wolf E, Roberts A (2006) Persistent responses to brief stimuli: feedback excitation among brainstem neurons. J Neurosci 26:4026-4035

Li W-C, Sautois B, Roberts A, Soffe SR (2007) Reconfiguration of a vertebrate motor network: specific neuron recruitment and contextdependent synaptic plasticity. J Neurosci 27:12267-12276

Liao J, Fetcho JR (2009) Shared versus specialized glycinergic spinal interneurons in axial motor circuits of larval zebrafish. J Neurosci 28:12982-12992

Llinás R (1980) Electrophysiological properties of in vitro Purkinje cell somata in mammalian cerebellar slices. J Physiol 305:171-195

Llinás RR (1988) The intrinsic electrophysiological properties of mammalian neurons: insights into central nervous system function. Science 242:1654-1664

Lin MT, Luján R, Watanabe M, Adelman JP, Maylie J (2008) SK2 channel plasticity contributes to LTP at Schaffer collateral-CA1 synapses. Nat Neurosci 11(2):170-177

Madriaga MA, McPhee LC, Chersa T, Christie KJ, Whelan PJ (2004) Modulation of locomotor activity by multiple 5-HT and dopaminergic receptor subtypes in the neonatal mouse spinal cord. J Neurophysiol 92:1566-1576

Magee JC (1998) Dendritic hyperpolarization-activated currents modify the integrative properties of hippocampal CA1 pyramidal neurons. J Neurosci 18:7613-7624

Magistretti J, Alonso A (1999) Biophysical properties and slow voltagedependent inactivation of a sustained sodium current in entorhinal cortex layer-II principal neurons: a whole-cell and single-channel study. J Gen Physiol 114:491-509

Mahmood R, Restrepo CE, El Manira A (2009) Transmitter phenotypes of commissural interneurons in the lamprey spinal cord. Neuroscience 164(3):1057-1067
Matsushima T, Grillner S (1992) Neural mechanisms of intersegmental coordination in lamprey: local excitability changes modify the phase coupling along the spinal cord. J Neurophysiol 67-2:373-388

McCrea DA, Rybak IA (2008) Organization of mammalian locomotor rhythm and pattern generation. Brain Res Rev 57(1):134-146

McLean DL, Fan J, Higashijima S-I, Hale ME, Fetcho JR (2007) A topographic map of recruitment in spinal cord. Nature 446: $71-75$

McLean DL, Masino MA, Koh IYY, Lindquist WB, Fetcho JR (2008) Continuous shifts in the active set of spinal interneurons during changes in locomotor speed. Nat Neurosci 11:1419-1429

McPherson DR, Buchanan JT, Kasicki S (1994) Effects of strychnine on fictive swimming in the lamprey: evidence for glycinergic inhibition, discrepancies with model predictions, and novel modulatory rhythms. J Comp Physiol A 175:311-321

Mulholland PJ (2012) K(Ca) 2 channels: novel therapeutic targets for treating alcohol withdrawal and escalation of alcohol consumption. Alcohol 46(4):309-315

Mullins OJ, Hackett JT, Buchanan JT, Friesen WO (2011) Neuronal control of swimming behavior: comparison of vertebrate and invertebrate model systems. Prog Neurobiol 93(2):244-269

Munoz A, Munoz M, González A, tenDonkelaar H (1997) Spinal ascending pathways in amphibians: cells of origin and main targets. J Comp Neurol 378:205-228

Nanou E, El Manira A (2007) A postsynaptic negative feedback mediated by coupling between AMPA receptors and $\mathrm{Na}+$-activated $\mathrm{K}+$ channels in spinal cord neurones. Eur J Neurosci 25(2):445-450

Nanou E, Kyriakatos A (2008) Na+-mediated coupling between AMPA receptors and $\mathrm{KNa}$ channels shapes synaptic transmission. Proc Natl Acad Sci 52:20941-20946

Ngo-Anh TJ, Bloodgood BL, Lin M, Sabatini BL, Maylie J, Adelman JP (2005) SK channels and NMDA receptors form a Ca2+-mediated feedback loop in dendritic spines. Nat Neurosci 8:642-649

Nieuwenhuys R, ten Donkelaar HJ, Nicholson C, Smeets WJAJ (1998) The central nervous system of vertebrates, 3 volume cased set with poster book. Springer, New York

Ohta Y, Grillner S (1989) Mono-synaptic excitatory amino-acid transmission from the posterior rhombencephalic reticular nucleus to spinal neurons involved in the control of locomotion in lamprey. J Neurophysiol 62:1079-1089

Orlovsky G, Deliagina T, Grillner S, Orlovskii G (1999) Neuronal control of locomotion: from mollusc to man. Oxford University Press, New York

Ovsepian SV, Vesselkin NP (2006) Serotonergic modulation of synaptic transmission and action potential firing in frog motoneurons. Brain Res 1102:71-77

Pape HC (1996) Queer current and pacemaker: the hyperpolarizationactivated cation current in neurons. Annu Rev Physiol 58:299-327

Parker D, Grillner S (2000) The activity-dependent plasticity of segmental and intersegmental synaptic connections in the lamprey spinal cord. Eur J Neurosci 12:2135-2146

Perrier JF, Tresch MC (2004) Recruitment of motor neuronal persistent inward currents shapes withdrawal reflexes in the frog. J Physiol 562(2):507-520

Prinz AA, Bucher D, Marder E (2004) Similar network activity from disparate circuit parameters. Nat Neurosci 7(12):1345-1352

Ritter D, Bhatt D, Fetcho J (2001) In vivo imaging of zebrafish reveals differences in the spinal networks for escape and swimming movements. J Neurosci 21:8956-8965

Roberts A, Tunstall MJ (1990) Mutual re-excitation with post-inhibitory rebound: a simulation study on the mechanisms for locomotor rhythm generation in the spinal cord of xenopus embryos. Eur J Neurosci 2:11-23

Roberts A, Perrins R (1995) Positive feedback as a general mechanism for sustaining rhythmic and non-rhythmic activity. J Physiol Paris $89: 241-248$ 
Roberts A, Li WC, Soffe SR (2010) How neurons generate behavior in a hatchling amphibian tadpole: an outline. Front Behav Neurosci 4:16

Rybak IA, Shevtsova NA, Lafreniere-Roula M, McCrea DA (2006) Modelling spinal circuitry involved in locomotor pattern generation: insights from deletions during fictive locomotion. J Physiol 577:617639

Ryczko D, Lamarque S, Didier H, Cabelguen JM (2009) Dynamics of the axial locomotor network in the isolated spinal cord of the salamander. Society for Neuroscience, Program 565.8, Abstr. EE6.

Ryczko D, Charrier V, Ijspeert A, Cabelguen JM (2010a) Segmental oscillators in axial motor circuits of the salamander: distribution and bursting mechanisms. J Neurophysiol 104:2677-2692

Ryczko D, Dubuc R, Cabelguen J-M (2010b) Rhythmogenesis in axial locomotor networks: an interspecies comparison. Prog Brain Res 187:189-211

Satou C, Kimura Y, Kohashi T, Horikawa K, Takeda H, Oda Y, Higashijima S-I (2009) Functional role of a specialized class of spinal commissural inhibitory neurons during fast escapes in zebrafish. J Neurosci 29:6780-6793

Schroeder DM, Egar MW (1990) Marginal neurons in the urodele spinal cord and the associated denticulate ligaments. J Comp Neurol 301:93-103

Shen W, Slaughter MM (1999) Metabotropic GABA receptors facilitate L-type and inhibit N-type calcium channels in single salamander retinal neurons. J Physiol 516(Pt 3):711-718

Sirota MG, Di Prisco GV, Dubuc R (2000) Stimulation of the mesencephalic locomotor region elicits controlled swimming in semi-intact lampreys. Eur J Neurosci 12:4081-4092

Soffe SR (1989) Roles of glycinergic inhibition and N-methyl-Daspartate receptor mediated excitation in the locomotor rhythmicity of one half of the xenopus embryo central nervous system. Eur J Neurosci 1:561-571

Stafstrom CE, Schwindt PC, Crill WE (1982) Negative slope conductance due to a persistent subthreshold sodium current in cat neocortical neurons in vitro. Brain Res 236:221-226

Stephenson-Jones M, Samuelsson E, Ericsson J, Robertson B, Grillner S (2011) Evolutionary conservation of the basal ganglia as a common vertebrate mechanism for action selection. Curr Biol 21:1081-1091

Stocker M (2004) Ca2+-activated K+ channels: molecular determinants and function of the SK family. Nat Rev Neurosci 5:758-770
Tazerart S, Viemari JC, Darbon P, Vinay L, Brocard F (2007) Contribution of persistent sodium current to locomotor pattern generation in neonatal rats. J Neurophysiol 98:613-628

Tegnér J, Hellgren-Kotaleski J, Lansner A, Grillner S (1997) Lowvoltage-activated calcium channels in the lamprey locomotor network: simulation and experiment. J Neuro-physiol 77:1795-1812

Tråvén HG, Brodin L, Lansner A, Ekeberg Ö, Wallén P, Grillner S (1993) Computer simulations of NMDA and non-NMDA receptormediated synaptic drive: sensory and su-praspinal modulation of neurons and small networks. J Neurophysiol 70:695-709

Ullström M, Kotaleski JH, Tegnér J, Aurell E, Grillner S, Lansner A (1998) Activity-dependent modulation of adaptation produces a constant burst proportion in a model of the lamprey spinal locomotor generator. Biol Cybern 79:1-14

Vinay L, Grillner S (1993) The spino-reticulo-spinal loop can slow down the NMDA-activated spinal locomotor network in lamprey. Neuroreport 4:609-612

Wallén P, Ekeberg Ö, Lansner A (1992) A computer-based model for realistic simulations of neural networks. II. The segmental network generating locomotor rhythmicity in the lamprey. J Neurophysiol 68:1939-1950

Wallén P, Grillner S (1997) Central pattern generators and their interaction with sensory feedback. Proc Am Control Conf 5:2851-2855

Wallén P, Robertson B, Cangiano L, Löw P, Bhattacharjee A, Kaczmarek LK, Grillner S (2007) Sodium-dependent potassium channels of a slack-like subtype contribute to the slow afterhyperpolarization in lamprey spinal neurons. J Physiol (London) 585(1):75-90

Wang D, Grillner S, Wallén P (2011) 5-HT and dopamine modulates CaV1.3 calcium channels involved in postinhibitory rebound in the spinal network for locomotion in lam-prey. J Neurophysiol 105:1212-1224

Williams T, Grillner S, Smoljaninov V, Wallén P, Kashin S, Rossignol S (1989) Locomotion in lamprey and trout-the relative timing of activation and movement. J Exp Biol 143:559-566

Zhong G, Masino MA, Harris-Warrick RM (2007) Persistent sodium currents participate in fictive locomotion generation in neonatal mouse spinal cord. J Neurosci 27:4507-4518 